

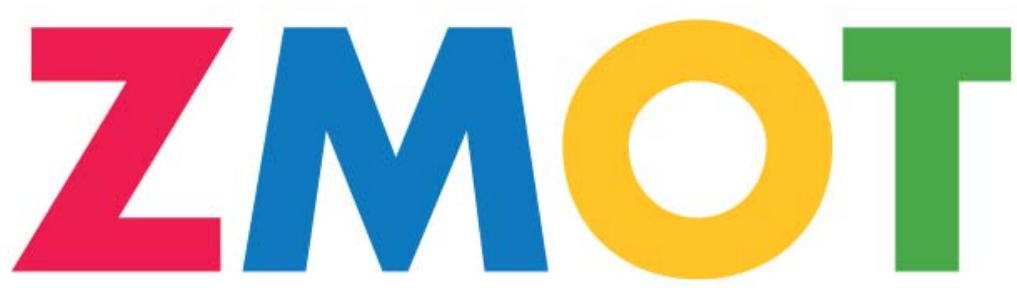

ЗАВОЕВАНИЕ

НУАЕВОГО

MOMEНТА ИСТИНЫ

Ажим Аесински

Google 



\section{ОГЛАВЛ Н Н И}

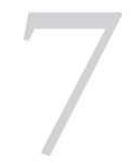

ПРЕДИСЛОВИЕ

Дина Хауэлл

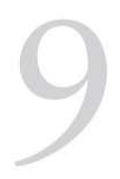

ГЛАВА 1:

Меняем свод

правил

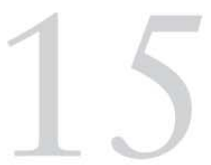

ГЛАВА 2:

Новая ментальная модель
ГЛАВА 3:

Кругом ZMOT
ГЛАВА 4:

Рейтинги и отзывы: из уст в MOT

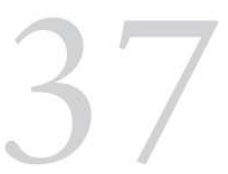

глАвА 5: Внимание наравне с остальными, а не в последнюю очередь

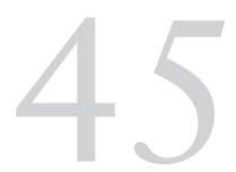

ГЛАВА 6:

Как завоевать ZMOT
ГЛАВА 7:

Что дальше?

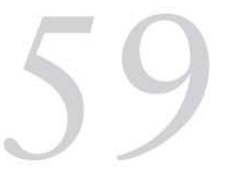

Двигайтесь вперёд

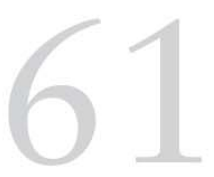

Приложение

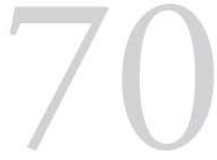

Сноски

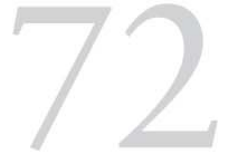

Благодарности

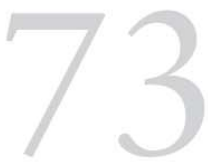

Об авторе 



\section{П Р ЕДИСЛО В И Е}

\section{АИНА ХАУЭМА}

\section{CEO, SaAtchi \& $S_{\text {aAtchi }} \mathrm{X}$}

Я страстно увлечена маркетингом. Я считаю, что потребители сами скажут нам, чего они хотят и что им нужно в жизни, если только мы будем прислушиваться к ним снова и снова каждый день.

B Saatchi \& Saatchi X мы недавно провели исследование с целью понять, какие эмоциональные выгоды влияют на покупательское поведение и управляют им. Эти выгоды, как мы выяснили, включают в числе прочего удовлетворение глубоких потребностей самосозидания, приобретения новых знаний, безопасности и выстраивания взаимоотношений.

Сегодня покупатели хотят узнавать и думать о том, как товары могут улучшить их жизнь. Они проводят исследования с целью получить интересующие их сведения, и ими движет желание устанавливать связи с другими людьми и обогащать эти отношения по мере того, как они узнают новое. Они мотивированы желанием взять на себя ответственность за их собственные личности и благополучие их семей и домохозяйств.

Процесс удовлетворения этих потребностей покупателей начинается с Нулевого Момента Истины.

Большинство из нас понимает важный момент принятия решения рядом с полкой - Первый Момент Истины (First Moment Of Truth, FMOT), как мы его назвали в то время, когда я работала в Procter \& Gamble. Однако сегодняшние потребители уже знают гораздо больше ещё до того, как они достигнут магазинной полки.
Они находят невероятное количество сведений о брэндах и продуктах, которые имеют для них значение, онлайн, из всех возможных источников. Они просматривают, раскапывают, исследуют, выдумывают и осваивают, и после этого они готовы покупать с уверенностью. И тем, что они узнали, они делятся с другими.

Нулевой Момент Истины влияет на то, какие брэнды попадают в список покупок, где совершаются покупки, и с кем покупатели делятся результатами. Нам решать, присоединиться ли к разговору в этот новый момент принятия решения и предоставить информацию, которую так жаждут получить покупатели, всеми способами, какими они хотят её получить.

Я знакома с Джимом Лесински и почитаю его на протяжении многих лет. Он и его команда Google являлись надёжными коллегами и советниками в период удивительного роста и появления новых возможностей онлайн мира во время моей работы в Procter \& Gamble, и продолжают быть ими сейчас, когда я нахожусь в роли руководителя агентства.

Эта книга поможет каждому, кому интересны эти новые моменты перед тем, как люди совершат покупку - эти Нулевые Моменты Истины, когда возникают первые впечатления, с которых часто начинается путь к покупке. Если вы заботитесь о том, чтобы помочь покупателям исследовать, выдумать и найти то, что они ищут - короче говоря, если вы страстно заинтересованы будущим маркетинга - эта книга для вас. 


\section{CHANGING THE RULEBOOK}

RULEBOOK CHANGING THE RULEBOOK CHANGING THE RULEBOOK CHANGING THE VG THE RULEBOOK CHANGING THE RULEBOOK CHANGING THE RULEBOOK CHANGIN GING THE RULEBOOK CHANGING THE RULEBOOK CHANGING THE RULEBOOK CHAN JGING THE RULEBOOK CHANGING THE RULEBOOK CHANGING THE RULEBOOK CHAN CHANGING THE RULEBOOK CHANGING THE RULEBOOK CHANGING THE RULEBOOK

CHANGING THE RULEBOOK CHANGING THE RULEBOOK CHANGING THE RULEBO ULEBOOK CHANGING THE RULEBOOK CHANGING THE RULEBOOK CHANGING THE R RULEBOOK CHANGING THE RULEBOOK CHANGING THE RULEBOOK CHANGING THE CHANGING THE RULEBOOK CHANGING THE RULEBOOK CHANGIN GING THE RULEBOOK CHANGING THE RULEBOOK CHANGING THE RULEBOOK CHAN IGING THE RULEBOOK CHANGING THE RULEBOOK CHANGING THE RULEBOOK CHAN CHANGING THE RULEBOOK CHANGING THE RULEBOOK CHANGING THE RULEBOOK

CHANGING THE RULEBOOK CHANGING THE RULEBOOK ULEBOOK CHANGING THE RULEBOOK CHANGING THE RULEBOOK CHANGING THE R RULEBOOK CHANGING THE RULEBOOK CHANGING THE RULEBOOK CHANGING THE CHANGING THE RULEBOOK CHANGING THE RULEBOOK CHANGIN GING THE RULEBOOK CHANGING THE RULEBOOK CHANGING THE RULEBOOK CHAN IGING THE RULEBOOK CHANGING THE RULEBOOK CHANGING THE RULEBOOK CHAN CHANGING THE RULEBOOK CHANGING THE RULEBOOK

CHANGING THE RULEBOOK CHANGING THE RULEBOOK CHANGING THE RULEBOr ULEBOOK CHANGING THE RULEBOOK CHANGING THE RULEBOOK CHANGING THE R RULEBOOK CHANGING THE RULEBOOK CHANGING THE RULEBOOK CHANGING THE CHANGING THE RULEBOOK CHANGING THE RULEBOOK CHANGI GING THE RULEBOOK CHANGING THE RULEBOOK CHAN IGING THE RULEBOOK CHANGING THE RULEBOOK CHANGING THE RULEBOOK CHAN CHANGING THE RULEBOOK CHANGING THE RULEBOOK CHANGING THE RULEBOOK CHANGING THE RULEBOOK CHANGING THE RULEBO ULEBOOK CHANGING THE RULEBOOK CHANGING THE RULEBOOK CHANGING THE R RULEBOOK CHANGING THE RULEBOOK CHANGING THE RULEBOOK CHANGING THE CHANGING THE RULEBOOK CHANGING THE RULEBOOK CHANGIN GING THE RULEBOOK CHANGING THE RULEBOOK CHANGING THE RULEBOOK CHAN IGING THE RULEBOOK CHANGING THE RULEBOOK CHANGING THE RULEBOOK CHAN CHANGING THE RULEBOOK CHANGING THE RULEBOOK CHANGING THE RULEBOOK CHANGING THE RULEBOOK JLEBOOK CHANGING THE RULEBOOK CHANGING THE RULEBOOK CHANGING THE R RULEBOOK CHANGING THE RULEBOOK CHANGING THE RULEBOOK CHANGING THE 


\section{ГЛ А B A}

1

\section{MEHЯ П РАВИЛ}

«Сегодня, когда потребители слышат о товаре, их первая реакция такова: 'Дай-ка я посмотрю об этом в Интернет.' Таким образом, они отправляются в путь открытий: о продукте, об услуге, о проблеме, о возможности.

Сегодня вы находитесь не позади конкурентов. Вы не позади технологии. Вы находитесь позади вашего потребителя.»

- РИШАД ТОБАКОваЛА

ДИРЕКТОР ПО СТРАТЕГИИ И ИННОВАЦИЯМ

VIVAKI

Время от времени что-то появляется и меняет своА правиА.

Несколько месяцев назад я останавливался в довольно большом отеле в Нью-Йорке. По пути в номер я заметил плакат в вестибюле: «Приходите сегодня вечером к 8 p.m. в танцевальный зал на выступление Max Weinberg Band.»

Получается, теперь мне нравится Макс Вейнберг. Таким образом, это был классический случай маркетинга: Стимулом являлся плакат - «Приходите на Макса Вейнберга!» - a моим откликом очевидно было бы спуститься в танцевальный зал в восемь, купить билет и посмотреть шоу.

Но я этого не сделал.

Вместо этого я поднялся в номер, открыл ноутбук и начал искать. Потому что я хотел знать, «Какую музыку он играет? Что у него за группа? Сколько это стоит? Что из себя представляет танцевальный зал?» И после того, как я узнал ответы, я принял решение.

Зачем я рассказываю вам об этом?

Потому что этот маленький эпизод является тем самым эпизодом, который меняет набор маркетинговых правил. Это новый момент принятия решения, который возникает сотни миллионов раз в день на мобильных телефонах, ноутбуках, а также проводных устройствах всех типов. Это момент, когда происходит маркетинг, когда возникает информация и когда потребители совершают выбор, который влияет на успех или провал почти любого брэнда в мире.

B Google мы называем это Нулевым Моментом Истины (Zero Moment Of Truth, или просто ZMOT - произносится «ЗИИ-мот»). ${ }^{1}$ 


\section{Нулевой Момент Истины - это:}

ЗАНЯТАЯ МАМА, которая ищет противоотёчное средство с помощью своего мобильного телефона, пока она ждёт в машине своего сына из школы.

ОФИС-МЕНЕДЖЕР НА СВОЁМ РАБОЧЕМ МЕСТЕ, сравнИвающая ценЫ на лазерные принтеры и картриджи перед тем, как отправиться в магазин офисных товаров.

СТУДЕНТ В КАФЕ, просматривающий рейтинги и обзоры пользователей в поисках дешёвой гостиницы в Барселоне.

ЛЮБИТЕЛЬ ЗИМНИХ ВИДОВ СПОРТА В ЛЫЖНОМ МАГАЗИНЕ, КОТОРЫЙ достаёт мобильный телефон, чтобы посмотреть видео-обзор новейших досок для сноубординга.

МОЛОДАЯ ДЕВУШКА В СВОЕЙ КВАРТИРЕ, КОторая ищет в Интернет пикантные подробности о своём новом молодом человеке перед первым свиданием.

ZMOT - это тот момент, когда вы берёте в руки свой ноутбук, мобильный телефон, или другое проводное устройство и начинаете изучать продукт или услугу (или потенциального партнёра), которые вы хотите опробовать или купить. Я уверен, вы понимаете, что я имею в виду - возможно, вы осуществляете такой поиск в Интернет каждый день.

\section{HO}

Удивит ли Вас, что 70\% американцев теперь утверждают, что они смотрят отзывы о товарах перед тем, как совершить покупку? 2

Или что 79\% потребителей теперь говорят, что они используют смартфон, чтобы помочь себе в процессе покупок?3

Или что 83\% мам говорят, что они проводят онлайнисследования после того, как увидят телевизионную рекламу интересующих их продуктов ${ }^{4}$ 
Нас больше не должны удивлять эти невероятные цифры. Это то, каким образом сегодня потребители живут, узнают информацию и принимают решения: из рейтингов и сайтов с отзывами, от друзей в социальных сетях, дома и в пути, и (более, чем когда-либо) из видео. Они получают информацию из результатов поиска, отзывов пользователей, звёздочных рейтингов, текстовых объявлений, графических объявлений, заголовков новостей, видео, и даже старых добрых официальных вебсайтов брэндов.

Короче говоря, они получают информацию и принимают решение в Нулевой Момент Истины.

$$
* * *
$$

\section{Позводьте сделать мне шаг назад.}

21 сентября 2005 года The Wall Street Journal опубликовал статью на заглавной странице, которая изменила лицо маркетинга.

Это была история о невероятной важности первых семи секунд после того, как покупатель подошёл к магазинной полке, заполненной моющими средствами, зубной пастой, или чем-то ещё. Помните старую фразу: «Ищите её в морозильнике Вашего супермаркета?» (Примечание переводчика: эта рекламная фраза хорошо известна жителям США.) Это тот момент, о котором мы говорим - когда вы стоите там, глядя на всю эту замороженную пиццу и решая, какую из них взять.

Procter \& Gamble назвал этот момент Первым Моментом Истины (First Moment Of Truth, или FMOT - произносится «ЭФФ-м⿻о一»). Этот момент был настолько важным для P\&G, что они создали отдельную позицию под названием «Директор по FMOT» и назначили на неё Дину Хауэлл. A The Wall Street Journal нашли это настолько значимым, что разместили статью на заглавной странице.

В том же году, в своём предисловии к выдающейся книге Кевина Робертса Lovemarks, CEO Procter \& Gamble A. Г. Лафли выразил это так:

Лучшие брэнды последовательно побеждают в двух моментах истинь. Первый момент возникает на магазинной полке, когда потребитель решает, покупать ему тот или иной брэнд. Второй возникает дома, когда он использует этот брэнд и получает от этого удовольствие, или же нет.

Мистер Лафли был прав тогда и по-прежнему прав сейчас. Эти первый и второй моменты истины по-прежнему важны сегодня.

\section{HO}

Сейчас появился новый важный момент принятия решения, который происходит до того, как покупатель приходит в супермаркет. Неважно, продаёте ли вы яхты, или бритвенный крем, первое впечатление ваших потребителей - и вполне возможно, окончательное решение - возникает в этот момент: ZMOT.

Маркетологи тратят невероятное количество энергии и денег на два первых момента истины. Однако новый вопрос звучит так: Побеждаете ли вы в Нулевом Моменте Истины?

$$
* * *
$$


Mы в Google потратили очень много времени, размышляя над этим вопросом.

Сейчас ZMOT является основным тренингом для всех членов команды продаж Google. Это часть нашего ДНК - не только в США, но и во всём мире. (Наша австралийская команда называет его, естественно, ZedMOT.)

Мы находимся в уникальной позиции, чтобы видеть всю мощь ZMOT: его силу помочь покупателям принять хорошие решения и его силу помочь компаниям рассказать свои истории в момент наибольшего воздействия. ZMOT превращает маленькие победы в большие - и потенциально большие победы в разочарования - миллионы раз в день, без остановки.

Чтобы определить действие ZMOT в цифрах, мы заказали большое исследование у независимой исследовательской компании Shopper Sciences. Они опросили 5000 покупателей по 12 различным подкатегориям, причём вопросы были составлены таким образом, чтобы показать, какие конкретно источники повлияли на решения о покупке. В этой книге я впервые поделюсь с вами результатами этого исследования.

Эта книга о преобразованиях и изменениях. Я собираюсь показать вам, как заставить эти изменения работать на вас и вашу компанию.

$$
* * *
$$

Если Вы относитесь к типу людей, которые любят забегать вперёд, то я расскажу вам прямо сейчас о том, что вы найдёте в этой книге.

- Путь к принятию решения о покупке изменился. ZMOT является жизненно важным новым добавлением к классическому процессу из трёх шагов: стимул, полка, опыт.

- То, что когда-то было сообщением, теперь является разговором. Покупатели сегодня находят и делятся своей собственной информацией о товарах, своими способами, в своё собственное время.

- Сообщения, передаваемые из уст в уста, имеют большую силу, чем когда-дибо. Впервые в человеческой истории, сообщения из уст в уста перенеслись в архивируемую цифровую среду.

- Никакой Момент Истины не является слишком незначитель-

ным. Если потребители проводят онлайн-исследования в отношении домов и здравоохранения, они будут это делать и в отношении бинтов и шариковых ручек.

- Моменты Истины сходятся. Наши мобильные устройства являются машинами Момента Истины. По мере того, как растёт использование мобильных устройств, нулевой, первый и второй моменты истины объединяются.

Я разговаривал о ZMOT с большим количеством ведущих маркетологов и поделюсь с вами их мудростью: как узнать, что ищут потребители, быть частью разговора и одержать победу. 
Глава 1: Меняем свод правил

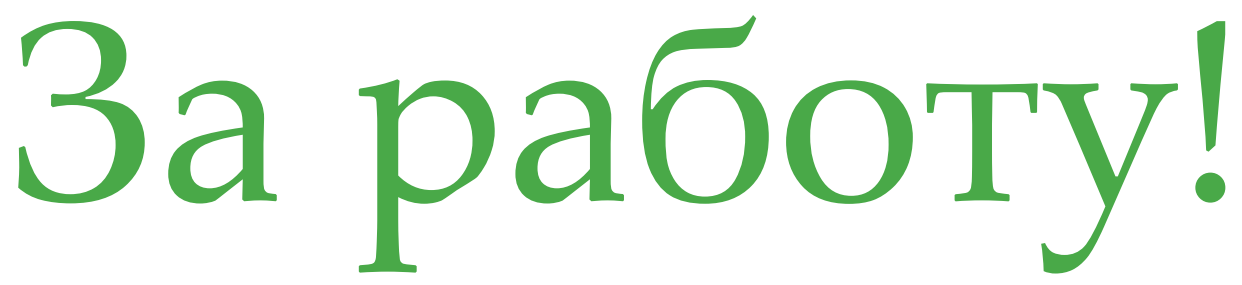


MODEL THE NEW MENTAL MODEL THE NEW MENTAL MODEL THE NEW MENTAL MODI LL THE NEW MENTAL MODEL THE NEW MENTAL MODEL THE NEW MENTAL MODEL THI HE NEW MENTAL MODEL THE NEW MENTAL MODEL THE NEW MENTAL MODEL. THE N E NEW MENTAL MODEL THE NEW MENTAL MODEL. THE NEW MENTAL MODEL THE NEY E NEW MENTAL MODEL THE NEW MENTAL MODEL THE NEW MENTAL MODEL. THE NEV HE NEW MENTAL MODEL THE NEW MENTAL MODEL THE NEW MENTAL MODEL. THE N E NEW MENTAL MODEL THE NEW MENTAL MODEL THE NEW MENTAL MODEL THE NEU E NEW MENTAL MODEL THE NEW MENTAL MODEL THE NEW MENTAL MODEL. THE NEV HE NEW MENTAL. MODEL THE NEW MENTAL. MODEL THE NEW MENTAL MODEL.

E NEW MENTAL MODEL THE NEW MENTAL MODEL THE NEW MENTAL MODEL THE NEИ NEW MENTAL MODEL THE NEW MENTAL MODEL THE NEW MENTAL MODEL. THE NEV HE NEW MENTAL MODEL THE NEW MENTAL MODEL THE NEW MENTAL MODEL THE N E NEW MENTAL. MODEL THE NEW MENTAL MODEL THE NEW MENTAL MODEL THE NEU NEW MENTAL MODEL THE NEW MENTAL MODEL THE NEW MENTAL. MODEL. THE NEV HE NEW MENTAL MODEL THE NEW MENTAL. MODEL THE NEW MENTAL MODEL

E NEW MENTAL MODEL THE NEW MENTAL MODEL THE NEW MENTAL MODEL THE NEИ E NEW MENTAL MODEL THE NEW MENTAL MODEL THE NEW MENTAL MODEL. THE NEV HE NEW MENTAL MODEL THE NEW MENTAL MODEL THE NEW MENTAL MODEL THE N E NEW MENTAL MODEL THE NEW MENTAL MODEL THE NEW MENTAL MODEL THE NEИ NEW MENTAL MODEL THE NEW MENTAL MODEL THE NEW MENTAL MODEL. THE NEV HE NEW MENTAL. MODEL THE NEW MENTAL MODEL THE NEW MENTAL MODEL. THE N E NEW MENTAL MODEL THE NEW MENTAL MODEL THE NEW MENTAL MODEL THE NEU NEW MENTAL MODEL THE NEW MENTAL MODEL THE NEW MENTAL. MODEL. THE NEV HE NEW MENTAL MODEL THE NEW MENTAL MODEL THE NEW MENTAL MODEL THE N E NEW MENTAL MODEL. THE NEW MENTAL MODEL THE NEW MENTAL MODEL THE NEU E NEW MENTAL MODEL THE NEW MENTAL MODEL THE NEW MENTAL MODEL THE NEV HE NEW MENTAL MODEL THE NEW MENTAL MODEL THE NEW MENTAL MODEL THE N E NEW MENTAL MODEL THE NEW MENTAL MODEL THE NEW MENTAL MODEL THE NEU NEW MENTAL MODEL THE NEW MENTAL MODEL THE NEW MENTAL MODEL. THE NEV HE NEW MENTAL MODEL THE NEW MENTAL MODEL THE NEW MENTAL MODEL. THE N E NEW MENTAL MODEL THE NEW MENTAL MODEL THE NEW MENTAL MODEL THE NEU NEW MENTAL MODEL THE NEW MENTAL MODEL THE NEW MENTAL MODEL THE NEV HE NEW MENTAL. MODEL THE NEW MENTAL MODEL. THE NEW MENTAL MODEL THE N E NEW MENTAL. MODEL THE NEW MENTAL MODEL THE NEW MENTAL MODEL THE NEИ E NEW MENTAL MODEL THE NEW MENTAL MODEL THE NEW MENTAL MODEL THE NEV HE NEW MENTAL MODEL THE NEW MENTAL MODEL THE NEW MENTAL MODEL. THE N E NEW MENTAL MODEL THE NEW MENTAL MODEL THE NEW MENTAL MODEL THE NEИ NEW MENTAL MODEL THE NEW MENTAL MODEL THE NEW MENTAL MODEL. THE NEV HE NEW MENTAL MODEL THE NEW MENTAL MODEL THE NEW MENTAL MODEL THE N E NEW MENTAL MODEL THE NEW MENTAL MODEL THE NEW MENTAL MODEL THE NEИ NEW MENTAL MODEL THE NEW MENTAL MODEL THE NEW MENTAL MODEL. THE NEV HE NEW MENTAL MODEL THE NEW MENTAL MODEL THE NEW MENTAL MODEL. THE N NEW MENTAL MODEL THE NEW MENTAL MODEL THE NEW MENTAL MODEL THE NEY NEW MENTAL MODEL THE NEW MENTAL MODEL THE NEW MENTAL MODEL. THE NEV HE NEW MENTAL MODEL THE NEW MENTAL MODEL THE NEW MENTAL MODEL THE N E NEW MENTAL MODEL THE NEW MENTAL MODEL THE NEW MENTAL MODEI THE NEU 


\title{
ГЛ А B A
}

2

\section{НОВ АЯ МЕНТА^ ВНАЯ МОДЕЛ Ь}

«Встреча с потребителем сегодня - это не просто разбрызгивание сообщения на их головы в надежде на то, что они намокнут.

Это на самом деле понимание того, что вы должны присутствовать в разговоре в тот момент, когда они хотят купить, а не когда вы хотите продать. Пред-покупка перед приобретением составляет огромную долю в поведении потребителя. В прошлом это ограничивалось дорогостоящими вещзами, такими как автомобили, дорогая әлектроника, или недвижимость. Сейчас люди проводят исследования перед покупкой даже для самых недорогих вещзей. Это пересекло все категории покупательского поведения. Это просто то, как люди совершают покупки сегодня.»

\author{
- БОБ ТАКЕР \\ СТРАТЕГИЧЕСКИЙ КОНСУЛЬTAHT GRAVITYTANK \\ И БЫВШИЙ ДИРЕКТОР ПО МАРКЕТИНГУ ОFFІСЕМАХ
}

«Человек не может пробежать милю менее, чем за 4 минуты. Это просто невозможно.І

Звучит нелепо? Сегодня - да. Однако на протяжении десятилетий это была общепринятая точка зрения. Это была ментальная модель: предположение о том, как работает мир. Вот как рассказывает эту историю профессор Джерри Винд из Wharton School:

Миля за четыре минуть казалась физическим препятотвием, которое люди не могут преодолеть... вилоть до 6 мая 1954 года.
В этот день Роджер Баннистер на соревнованиях в Оксфорде пробежал милю за 3:59.4. Он сломал барьер. Неожиданно, в течение следуюших трёх лет, ещзё 16 бегунов преодолели этот рубеж.

Был ли это прорыв в эволюичи человека? Нет. Изменилась ментальная модель.

Как часто случается, в маркетинге тоже существует классическая ментальная модель. На протяжении десятилетий мы совершенствовали наше ремесло, фокусируясь на трёх основных моментах: стимул, полка и опыт. 
Стимул. Отец семейства смотрит футбольный матч и видит рекламу цифровых камер. Он думает: «выглядит здорово.»

Полка. Он идёт в свой любимый магазин электроники, где натыкается на изумительный стенд той самой камеры. Упаковка великолепна. Молодой продавец отвечает на все его вопросы. Он покупает камеру.

Опыт. Отец семейства возвращается домой, камера записывает прекрасные фото его детей, как и было обещано в рекламе. Счастливое завершение.

Эти три шага и были ментальной моделью маркетинга на протяжении длительного времени.

\section{Рисунок 2-1: Тралиционная ментальная молель, состоящая из трёх шагов}

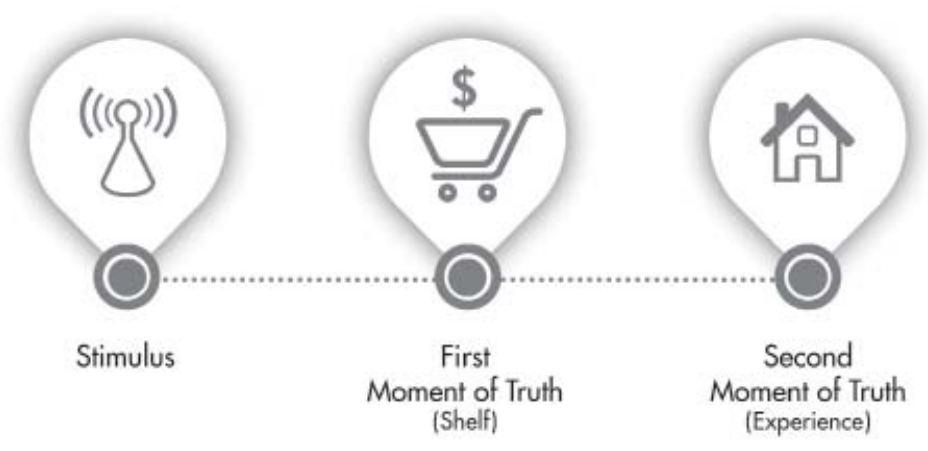

Однако большой новостью для маркетологов сегодня является важный новый момент между стимулом и полкой в каждой товарной категории. Отец семейства по-прежнему смотрит футбольный матч и по-прежнему видит ваш рекламный ролик. Но теперь он берёт свой ноутбук с кофейного столика и вводит в поисковой строке браузера «обзор цифровых камер». Он смотрит на комментарии пользователей на CNET и двух других сайтах. Он идёт в Твиттер и отправляет сообщение: «У кого-нибудь есть хорошая камера дешевле $\$ 100$ ?» Он открывает YouTube и ищет «примеры сьёмки цифровой камерой». И ещё до того, как закончится игра - и до того, как он приблизится к магазинной полке - он готов принять решение.

Если вы - брэнд-менеджер, то у вас есть политики, методики, тренинги, потребительские маркетинговые агентства, партнёры и бюджеты для того, чтобы победить в этих исходных трёх категориях стимула, полки и опыта.

Что вы имеете в своём арсенале, чтобы победить в этот «момент взятия ноутбука» - Нулевой Момент Истины?

Верятно, немногое. И вы не одиноки. Согласно Forrester Research, американские домохозяйства сейчас трятят столько же времени на Интернет, сколько на просмотр ТВ. Однако всего лишь около 15\% от общего бюджета медийных рекламных компаний было потрачено онлайн в 2010 году. ${ }^{1}$ Принятие решений в режиме онлайн взлетает до небес; онлайн маркетинговые бюджеты - нет. 
Измените свою ментальную модель маркетинга, включив в неё ZMOT, и вы сможете получить существенное конкурентное преимущество. Потому что вы дотянитесь до миллионов покупателей, которые принимают решения до того, как войдут в магазин.

\section{Рисунок 2-2: Новая ментальная молель}

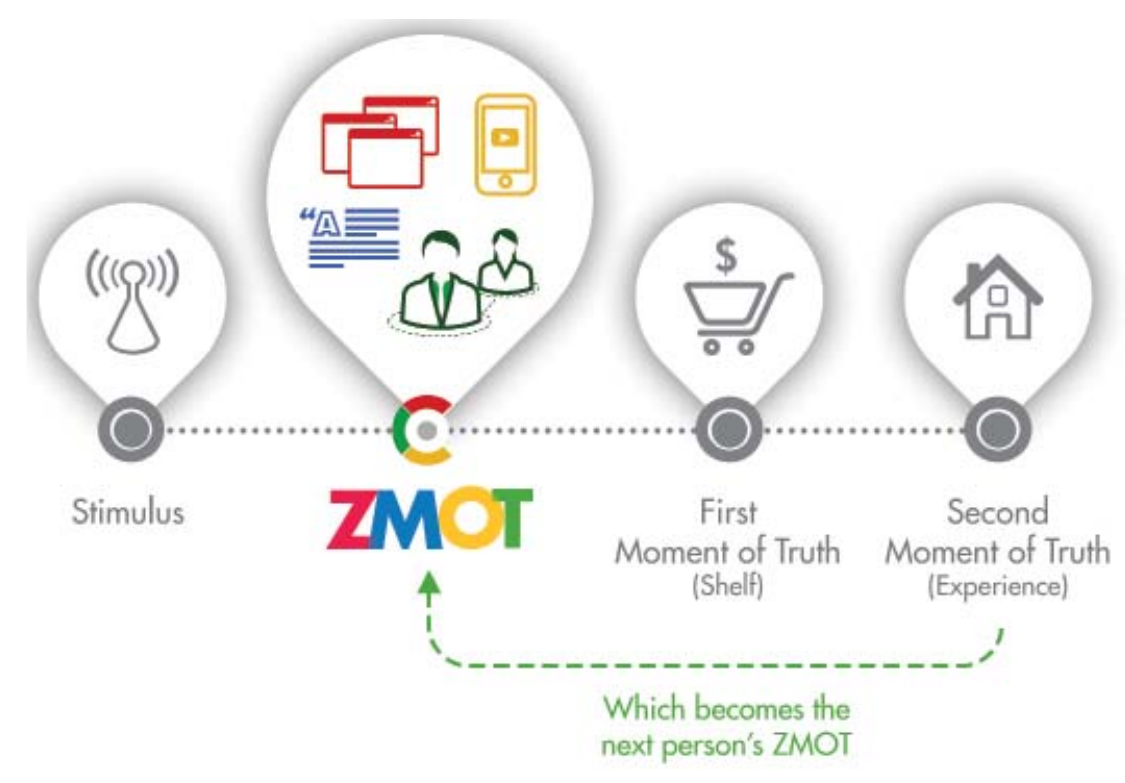

И кстати, мы говорим не только о магазинах и потребительских товарах. ZMOT работает во всех индустриях, в сегментах В2В и В2С, а также в таких областях, как образование и политика. Избиратели по-прежнему видят традиционные плакаты и листовки с лозунгами типа «Голосуй за Иванова». Но точно так же, как отец семейства, который выбирал новую камеру, избиратели сегодня принимают значительно больше решений до того, как подойдут к избирательной урне, во время Нулевого Момента Истины.

$$
* * *
$$

Так насколько же важен ZMOT в принятии решений? Google попросили Shopper Sciences выполнить всесторонее исследование среди 5000 покупателей по 12 категориям, от супермаркетов до автомобилей и финансовых продуктов. Цель: показать, в каком месте возникает влияние в процессе того, как покупатели переходят из категории колеблющцихся в категорию принявиих решение.

Данные показали, что средний покупатель использовал в 2011 году для принятия решения 10.4 источников информации, по сравнению с 5.3 источниками в 2010 году. ${ }^{2}$ Да, эта величина практически удвоилась за год, что показывает нам, насколько тяжело маркетологам сегодня привлечь внимание потребителей. Покупатели купаются в информации. Эти 10.4 источников включают в себя телевизионные ролики, журнальные статьи, рекомендации друзей и членов семьи, веб-сайты, онлайн рейтинги и блоги.

Мы выяснили, что множество пред-покупок производится в каждой категории. Покупатели добывают больше информации, из большего количества источников, прежде чем покупают. Вот как эти источники выглядят в виде диаграммы, разделённые на стимулы, ZMOT и FMOT. 
Рисунок 2-3: ГАавные источники, используемые покупателями Аля принятия решений о покупке по типам (источники, которые набрали более 17\% голосов)

\section{Стиму^}

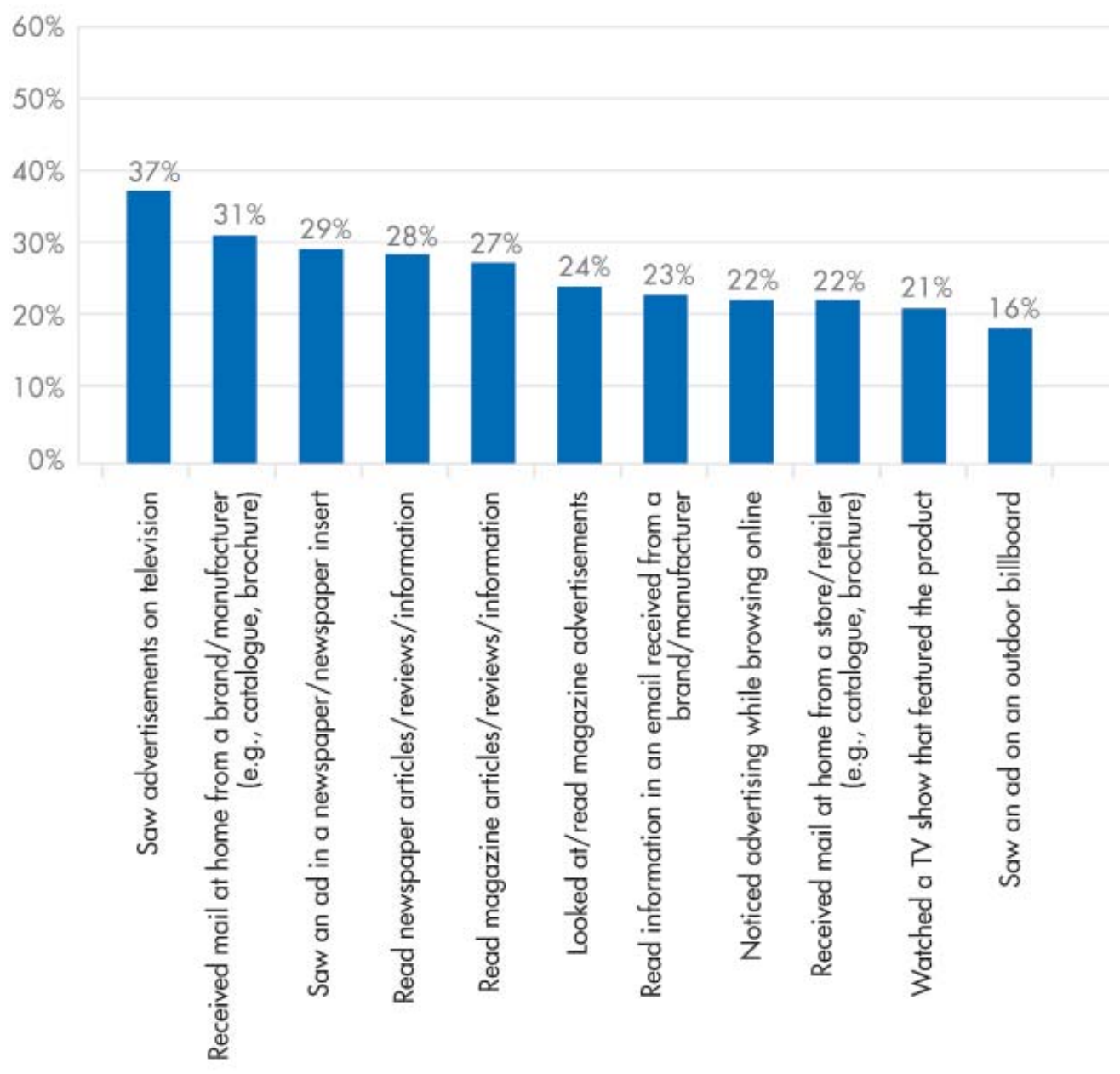

Q2 When you were considering purchasing [PRODUCT] what sources of information did you seek out to help with your decision?

Base $\quad \mathrm{N}=5,003$

Source: Google/Shopper Sciences, Zero Moment of Truth Macro Study, U.S., April 2011 
ZMOT

FMOT

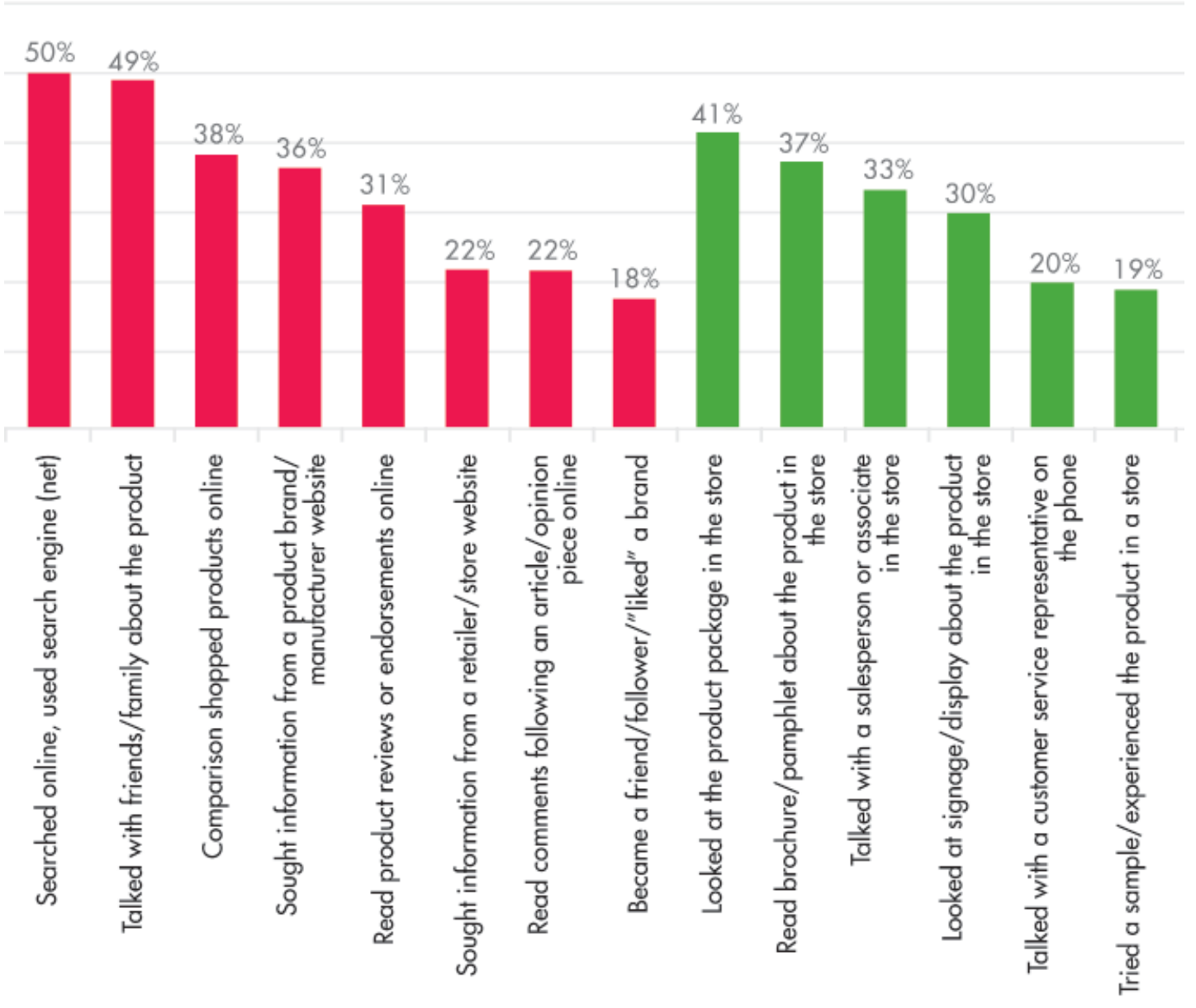


Суммарные значения:

Рисунок 2-4: Используемые источники по типам

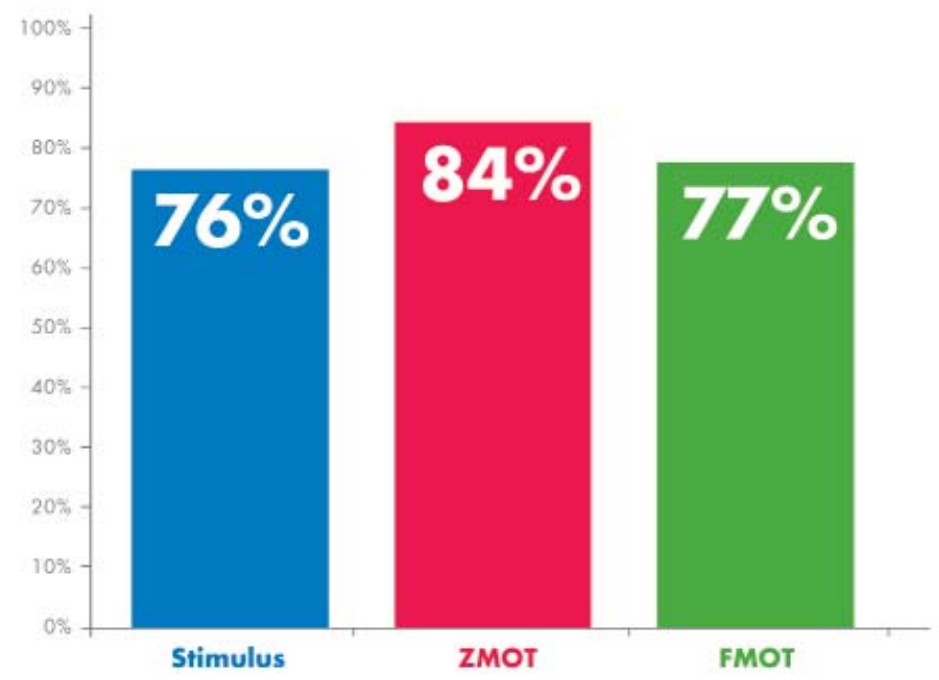

Q2 When you were considering purchasing [PRODUCT] what sources of information did you seek out to help with your decision?

Base $\mathrm{N}=5,003$

Source: Google/Shopper Sciences, Zero Moment of Truth Macro Study, U.S., April 2011

В нашем исследовании, 84\% респондентов отметили, что их решения оформляет ZMOT. Таким образом, он настолько же важен, как стимул и FMOT в процессе перевода потребителей из категории колеблющихся в категорию принявших решение.

$$
* * *
$$

То, что покупатели любят проводить исследования, конечно не является чем-то удивительным. Покупатели всегда общались между собой за дверями магазина и сами оценивали товары.

Как сказал Боб Такер в самом начале этой главы, решительные покупатели отправились бы в библиотеку, чтобы посмотреть, что написано в Consumer Reports про автомобили или стиральные машины. Существовали и другие исследовательские инструменты: Mobil Travel Guide содержал советы касательно гостиниц. Путеводители Загата давали подсказки по ресторанам. (Они даже выпускались в форме карманного справочника - мобильное приложение в книжной форме!) Однако для большинства вещей простота доступа оказывалась барьером. Наличие свежей и подробной информации о конкретном товаре было исключением.

\section{Это исключение теперь является правидом.}

Не существует барьеров для доступа. Сегодняшние покупатели носят «доступ» в своих карманах. Они создают свои собственные потребительские руководства миллион раз в минуту с помощью обзоров, твитов, блогов, публикаций в социальных сетях и видео о товарах всех типов.

Это просто новая ментальная модель и новый разговор, частью которого с этого времени мы все должны являться. 
Procter \& Gamble, создатели FMOT, видят ту же тенденцию. Недавно я разговаривал со своими друзьями в $\mathrm{P} \& \mathrm{G}$ - они делают большой акцент на то, что они называют "store back" - это побуждение маркетологов думать о каждом из потребительских восприятий брэнда «в обратную сторону» от магазинной полки до моментов, предшествующих посещению магазина.

Говоря о FMOT, обратите внимание, что все три изначальных шага - стимул, полка, опыт - по-прежнему необходимы. Стимул по-прежнему должен побуждать потребителя думать о цифровой камере. Мы по-прежнему хотим помочь потребителям принять правильные решения и выбрать наш брэнд.

Изменение заключается в том, что стимул теперь приводит потребителей к новой промежуточной остановке на пути к полке. Когда тот покупатель камеры начал свой поиск, информация не «пролилась» на него - вместо этого он активно за ней охотился и выбирал то, что хотел увидеть.

Ким Кадлек, вице-президент Глобальной Маркетинговой Группы Johnson \& Johnson, следующим образом описывает изменение ментальных моделей:

Mы вступаем в эпоху сотрудниества. Теперь мы должны вовлекать людей таким образом, чтобы это было им полезно или помогало в их жизни. Потребитель желает удовлетворить свои потребности, и мы должнь быть там, чтобы помочь ему с этим. Говоря другими словами: как м⿱⺌兀 можем обмениваться цзенностью, вместо того, чтобы просто посылать сообщение?

Чудесный потенциал здесь, если вы захотите этим заняться, заключается в установке тесной связи с потребителями. А это приводит к наивысшему моменту истины - когда потребитель покупает ваш товар снова.

$$
* * *
$$

Прямо сейчас возьмите в руки свой ноутбук или смартфон - бьюсь об заклад, они находятся где-то рядом с вами - и откройте свой любимый поисковик. Введите название флагманского продукта вашей компании, или любого другого продукта, который вам нравится.

Возможно, вы увидите в первых строках результатов поиска название официального сайта брэнда этого продукта. Пока всё идёт хорошо.

Теперь введите название этого же продукта и добавьте слово «отзывы». Затем запустите новый поиск и добавьте слово «лучший» для вашей продуктовой категории: лучший юридический ВУЗ, лучшая цифровая камера, лучшая гостиница во Флориде, и тому подобное. Что ещё вы видите на странице? Бьюсь об заклад, вы видите сайты с рейтингами и мнениями, онлайн-магазины, купоны, изображения, демонстрационные видео... и сайты конкурентов.

Это та информация, которую исподьзуют ваши покупатеди для принятия решения.

Мой вопрос к вам: вы довольны тем, что видите? Основываясь на том, что вы видите, ктонибудь купит ваш товар? Могут ли они в принципе найти ваш товар?

Это новая цифровая полка. Потребители прибывают сюда, круглосуточно, готовые к действию. Кто угодно может выиграть или проиграть в борьбе за них. Возможность потрясающая; вы готовы к этому?

Мировой рекорд времени забега на одну милю, кстати, сейчас составляет $3: 43.13 .^{3}$ 
ZMOT ALL AROUND US ZMOT ALL AROUND US ZMCT

UND US ZMOT ALL AROUND US ZMOT ALL AROUND US ZMOT ALL AROUND US ZM AROUND US ZMOT ALL AROUND US ZMOT ALL AROUND US ZMOT ALL ARO JND US ZMOT ALL AROUND US ZMOT ALL AROUND US ZMOT ALL AROUND US ZMO ZMOT ALL AROUND US ZMOT ALL AROUND US ZMOT ALL AROUN UND US ZMOT ALL AROUND US ZMOT ALL AROUND US ZMOT ALL AROUND US ZM MOT ALL AROUND US ZMOT ALL AROUND US ZMOT ALL. AROUND US ZMOT ALL ARC JND US ZMOT ALL AROUND US ZMOT ALL AROUND US ZMOT ALL AROUND US ZMO ZMOT ALL AROUND US ZMOT ALL AROUND US ZMOT ALL AROUN UND US ZMOT ALL AROUND US ZMOT ALL AROUND US ZMOT ALL AROUND US ZM MOT ALL AROUND US ZMOT ALL AROUND US ZMOT ALL AROUND US ZMOT ALL ARC UND US ZMOT ALL AROUND US ZMOT ALL AROUND US ZMOT ALL AROUND US ZMO ZMOT ALL AROUND US ZMOT ALL AROUND US ZMOT ALL AROUN UND US ZMOT ALL AROUND US ZMOT ALL AROUND US ZMOT ALL AROUND US ZM MOT ALL AROUND US ZMOT ALL AROUND US ZMOT ALL AROUND US ZMOT ALL ARC UND US ZMOT ALL AROUND US ZMOT ALL AROUND US ZMOT ALL AROUND US ZMO ZMOT ALL AROUND US ZMOT ALL AROUND US ZMOT ALL AROUN UND US ZMOT ALL AROUND US ZMOT ALL AROUND US ZMOT ALL AROUND US ZM MOT ALL AROUND US ZMOT ALL AROUND US ZMOT ALL AROUND US ZMOT ALL ARC UND US ZMOT ALL AROUND US ZMOT ALL AROUND US ZMOT ALL AROUND US ZMO ZMOT ALL AROUND US ZMOT ALL AROUND US ZMOT ALL AROUN UND US ZMOT ALL AROUND US ZMOT ALL AROUND US ZMOT ALL AROUND US ZM MOT ALL AROUND US ZMOT ALL AROUND US ZMOT ALL AROUND US ZMOT ALL ARC UND US ZMOT ALL AROUND US ZMOT ALL AROUND US ZMOT ALL AROUND US ZMO ZMOT ALL AROUND US ZMOT ALL AW

UND US ZMOT ALL AROUND US ZMOT ALL AROUND US ZMOT ALL AROUND US ZM MOT ALL AROUND US ZMOT ALL AROUND US ZMOT ALL AROUND US ZMOT ALL ARO UND US ZMOT ALL AROUND US ZMOT ALL AROUND US ZMOT ALL AROUND US ZMO ZMOT ALL AROUND US ZMOT ALL AROUND US ZMOT ALL AROUN UND US ZMOT ALL AROUND US ZMOT ALL AROUND US ZMOT ALL AROUND US ZM MOT ALL AROUND US ZMOT ALL AROUND US ZMOT ALL AROUND US ZMOT ALL ARO UND US ZMOT ALL AROUND US ZMOT ALL AROUND US ZMOT ALL AROUND US ZMO ZMOT ALL AROUND US ZMOT ALL AROUND US ZMOT ALL AROUN UND US ZMOT ALL AROUND US ZMOT ALL AROUND US ZMOT ALL AROUND US ZM MOT ALL AROUND US ZMOT ALL AROUND US ZMOT ALL AROUND US ZMOT ALL ARC UND US ZMOT ALL AROUND US ZMOT ALL AROUND US ZMOT ALL AROUND US ZMO UMOT ALL AROUND US ZMOT ALL AROUND US ZN UND US ZMOT ALL AROUND US ZMOT ALL AROUND US ZMOT ALL AROUND US ZM MOT ALL AROUND US ZMOT ALL AROUND US ZMOT ALL. AROUND US ZMOT ALL ARC UND US ZMOT ALL AROUND US ZMOT ALL AROUND US ZMOT ALL AROUND US ZMO ZMOT ALL AROUND US ZMOT ALL AROUND US ZMOT ALL AROUN UND US ZMOT ALL AROUND US ZMOT ALL AROUND US ZMOT ALL AROUND US ZM MOT ALL AROUND US ZMOT ALL AROUND US ZMOT ALL AROUND US ZMOT ALL ARC UND US ZMOT ALL AROUND US ZMOT ALL AROUND US ZMOT ALL AROUND US ZMO ZMOT ALL AROUND US ZMOT ALL AROUND US ZMOT ALL AROUN UND US ZMOT ALL AROUND US ZMOT ALL AROUND US ZMOT ALL AROUND US ZM 


\section{ГЛ А B A}

3

\section{Z MOT BE 3 AE BOKP УГ H A}

"У всех нас были такие моменты в жизни, когда, стол напротив зеркала воскресным вечером, мы внезапно понимали, что надо бь сбросить пару лишних килограмлов.

В прошлом вы пошли бы на кухню, взяли бы телефонный справочник с верхней полки, и стали бы листать его, не зная даже, с какой категории начать. Однако сейчас вы сразу же отправитесь в Интернет. Количество немедленно доступной ZMOT информации, созданной брэндами и пользователями, изумляет.

Наша работа сейчас ведётся почти исключительно онлайн. У нас есть множество ресурсов для наших будущзих клиентов, неважно, усльшали ли они о нас в разговоре, или пережили свой собственный момент у зеркала. Даже воскресной ночью."

- Дэннис Кэри

ДИРЕКТОР ПО МАРКЕТИНГУ И СТАРШИЙ ВИЦЕ-ПРЕЗИДЕНТ

Bally Total Fitness

\section{Что созАаёт Нулевой Момент Истины?}

- Он возникает онлайн - обычно вместе с поиском в Google, Bing, Yahoo, YouTube, или любой другой поисковой машине.

- Он случается в реальном времени, в любое время суток. Всё чаще это происходит «на ходу»: за последний год количество поисковых запросов к Google с мобильных устройств удвоилось. ${ }^{1}$
- Действующим лицом является потребитель, разыскивая нужную информацию, а не получая её от других.

- Эмоциональный фактор. У потребителя есть потребность, которую необходимо удовлетворить, и эмоциональные инвестиции для поиска наилучшего решения.

- Разговор является многосторонним: маркетологи, друзья, незнакомцы, веб-сайты и эксперты - все они имеют голос и соревнуются между собой за внимание. 
В предыдущей главе я упомянул, что 84\% опрошенных в нашем исследовании Shopper Sciences 2011 Macro Study использовали онлайн-источники для помощи в принятии решений. Мы также попросили респондентов оценить, насколько влиятельным был каждый источник. Для тех, кто использовал онлайн-источники, следующее положение было ключевым:

\section{4\% сравнивали товары ондайн}

Изменилась не степень доступности информации о товаре, а то, как покупатели думают о нём. Маркетологи говорили о процессе покупки как о воронке: Потребители попадают внутрь через широкое входное отверстие при помощи рекламы или других стимулов, сужают свой выбор и вываливаются из узкого горлышка с покупкой. Это очень прямолинейный способ мышления.

Также как и я, поговорите с покупателями сегодня о том, каким путём они идут к покупке, и вы получите неожиданно нелинейные ответы. Как показывают эти новые данные от Shopper Sciences, поведение индивидуальных покупателей теперь является итеративным и нелинейным. Покупатели не всегда движутся внутри воронки, ограничивая свой выбор по мере продвижения; во время ZMOT они могут расширять возможности выбора. Чем больше они узнают, тем больше вариантов рассматривают.

Воронка теперь больше походит на нейрон, с ответвлениями, которые позволяют покупателям перемещаться вперёд или назад до тех пор, пока они не будут готовы принять решение.

Существует столько же мотиваций ZMOT и столько же его форм, как и пользователей онлайн. Вот некоторые классические «ZMOTивации»:

\section{Поиск и распространение новых идей}

Десять миллионов раз в день Google видит такие поисковые запросы: рецепт тыквенного хлеба, рецепты с низкил содержанием жира, чили в техасском стиле, сдоба без клейковинь, блюда на Благодарение, как сделать традиционное шоколадное печенье.

На самом деле, рецепты занимают долю в 1\% от всех поисковых запросов в Google. ${ }^{2}$ Сегодняшние пекари идут в Интернет, чтобы получить новые идеи и углубить знания о калорийности и ингридиентах. Они находят не только рецепты. Они находят истории и отчёты от продуктовых и семейных журналов, рейтинги на сайтах типа Epicurious.com, официальные сайты Duncan Hines, Pillsbury и Betty Crocker, и многое другое.

Конечно, рецепты можно по-прежнему найти на этикетках или упаковке продуктов. Однако сегодня многие покупатели делают выбор, что приготовить или испечь, до того, как окажутся в магазине.

\section{Подготовка к сражению}

Покупатель приходит в автосалон и говорит: «мне нужен Lexus 250h с туристическим пакетом, 2.4-литровым четырёхцилиндровым двигателем, двухзонным климат-контролем и кожаным салоном жёлто-коричневого цвета, с подогревом сидений. Я видела спецификации и читала онлайн-обзоры. Я знаю, что MSRP-цена на автомобиль $\$ 37,125$, но Ваша реальная цена $-\$ 33,686 . »^{3}$ 
Что произошло? Произошёл ZMOT. Этот покупатель начал свой путь к покупке автомобиля с поисковой фразы «седаны средней стоимости». Она посмотрела рекламные объявления семи других брэндов, статьи на MotorTrend.com и RideLust.com, а также многое другое.

Затем она переключилась на поиски типа "рейтинги Lexus 250» и нашла обзоры от AOL Autos, Epinions, Cars.com и нескольких других источников. Затем в поисках цен она отправилась на Edmunds и Kelley Blue Book. Наконец на официальном сайте Lexus она посмотрела варианты окраски, цвета салона и другие опции. Если вы недавно занимались покупкой автомобиля, вы могли видеть эту женщину в автосалоне с распечатками ZMOT в руках, или показывающей экран своего смартфона продавцу. Может быть вы сами и были той женщиной.

Shopper Sciences проанализировали источники влияния на покупателей автомобилей на протяжении всего периода покупки. Они задали покупателям вопросы: «Вы использовали поисковые машины в процессе принятия решения?», «Насколько большое влияние это оказывало на ваш выбор?» Затем они визуализировали результаты в виде вот этой тепловой карты:

Рисунок 3-1: Тепловая карта влияния поисковых машин Аля автомобилей

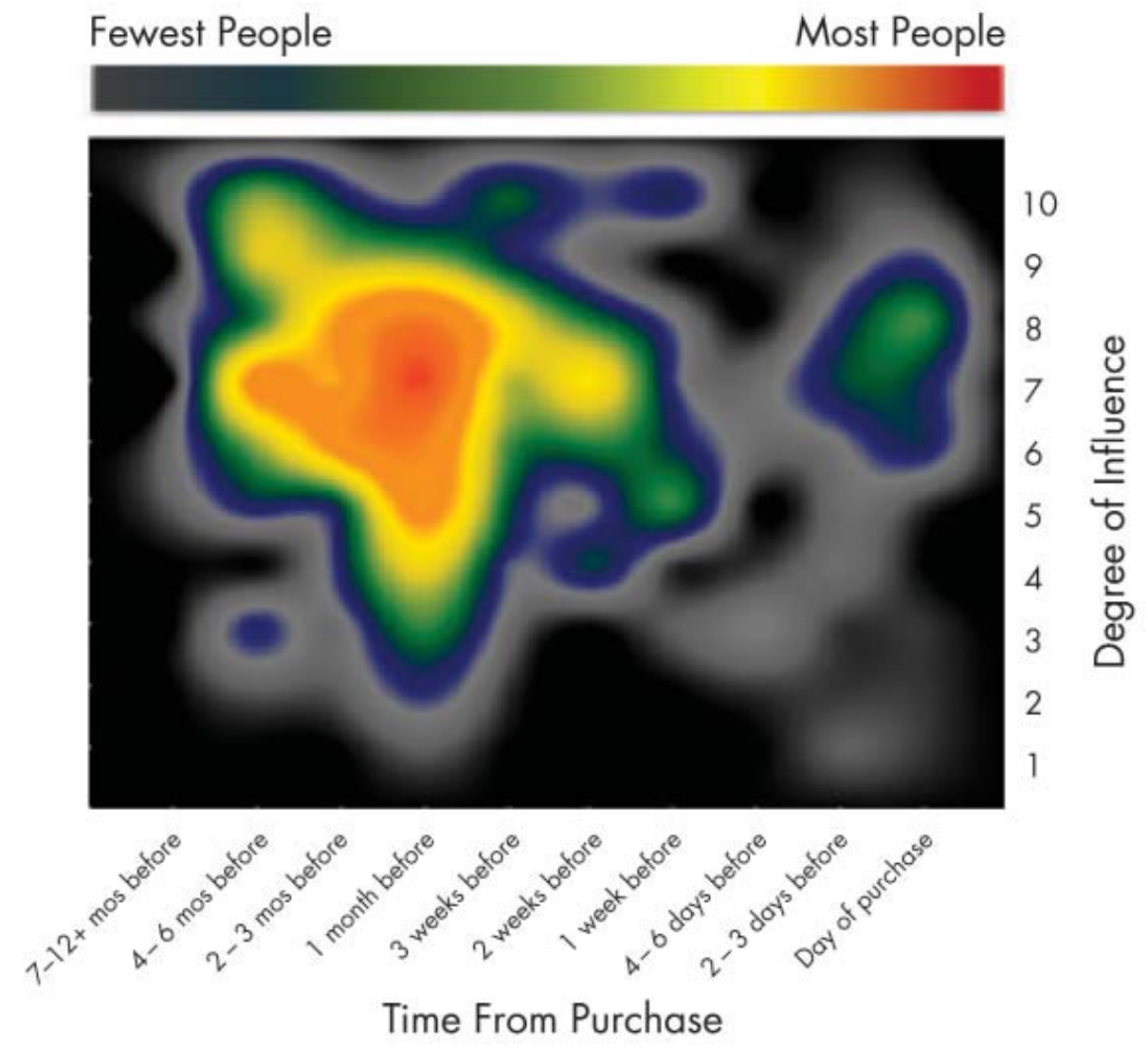

Base $\mathrm{N}=500$

Source: Google/Shopper Sciences, Zero Moment of Truth Automotive Study, U.S., April 2011 
На что покупатели автомобилей смотрят с помощью поисковых машин? Оказывается, 64\% смотрят на цены, $44 \%$ смотрят на технические характеристики и $37 \%$ смотрят на дизайн. ${ }^{4}$ Многие интересовались этими вопросами за 4 месяца до покупки.

\section{Быстрое принятие умных решений}

Давайте снова обратимся к занятой маме, которую мы упомянули в первой главе. Её ZMOT выглядит следующим образом: Она знает, что её сын заболел, и сейчас она припарковалась рядом со школой, и использует своё мобильное устройство для поиска противоотёчного средства. Она ищет:

1. Больше информации о продукте, а также

2. Опыт тех, кто уже пользовался этим средством, а также

3. Скидки, купоны, специальные предложения.

В этот момент она принимает два решения: что покупать и где покупать. Таким образом, если она видит, что данное средство имеет хорошие рейтинги, и что в её местной аптеке на это средство дают скидку в $2 \%$, то возможно, покупка уже состоялась.

$$
* * *
$$

Вы видите преимущество. Если вы доступны в Нулевой Момент Истины, ваши покупатели найдут вас в тот самый момент, когда они думают о покупке, а также когда они думают о том, чтобы подумать о покупке. Для наибольшего воздействия вы можете персонализировать своё сообщение всеми возможными способами.

Вы также можете отправить своё сообщение только тем людям, которым Вы хотите. Как отмечает Ким Кадлек из Johnson \& Johnson, «Вы можете доставить своё сообщение тысячам мам, у которых есть дети от 3 до 8 лет, а не просто тысяче женщин.»

Период времени, который потребители тратят на ZMOT, значительно больше времени, которое они тратят на магазинную полку. Вот подборка продолжительностей циклов покупки для трёх различных категорий: 


\section{Рисунок 3-2: СреАние циклы покупки по трём различным категориям}

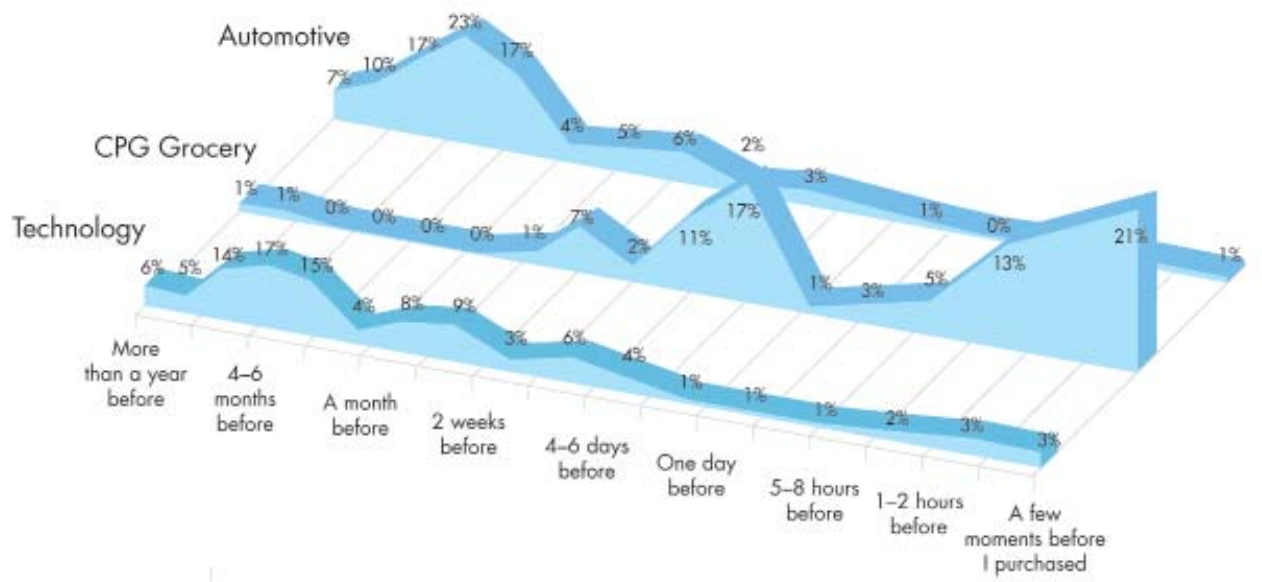

Source: Google/Shopper Sciences, Zero Moment of Truth Industry Studies, U.S., April 2011 Automotive $\mathrm{N}=500, \mathrm{CPG}$ Grocery $\mathrm{N}=500$, Tech $\mathrm{N}=500$

Это очень много времени.

Google изучал переходы по платной рекламе при помощи инструмента, который мы называем «анализ пауз поисковой рекламы», чтобы посмотреть, что происходит, когда рекламодатели отключают платный поиск. Мы посмотрели на сотни приостановленных кампаний, чтобы выяснить, могут ли рекламодатели заместить потерянные оплаченные переходы переходами с результатов обычного поиска. По большей части, они не могут: в среднем, 89\% оплаченных переходов были чисто инкрементивными. ${ }^{5}$

Если коротко, то в лице ZMOT у вас есть мощное оружие воздействия на потребителей в моменты «до посещения магазина».

$$
* * *
$$

ZMOT становится ещё более важным, когда бюджет ограничен.

Согласно Службе Труда США, средние расходы домовладений на продукты питания в 2010 году составляли $\$ 312$ в месяц. Если вы относитесь к обычной американской семье, то не можете позволить себе купить неправильное ореховое масло или замороженные ужины, потому что эти семь долларов, потраченные на неправильный продукт, означают, что вы не сможете себе позволить купить десерт или угощение для детей в конце месяца.

Кэтрин Рой, моя коллега из Google, привела отличный пример:

Рядом с нами живёт соседка, которая не является технически продвинутой. После того, как наступила рецессия, мығ как-то разговаривали и она сказала: «У меня четверо мальчиков и я провожу пять дней в неделю в супермаркете - это просто убивает нас. Через несколько лет нужно будет отправлять детей в колледж. Мне приилось начать анализировать то, каким образом я расходую деньги.» 
Она стала искать купонь через Интернет. В какой-то момент она разобралась с сайтахи типа Coupons.com, стала смотреть на реклалу и скидки в Интернет и планировать питание на неделю. Затем она начала искать в Интернет, что люди говорят о продуктах, которье она покупает. Это заразительно.

Она не называет әто ZMOT, но говорит, что теперь ходит в мигазин не пять, а один или два раза в неделю. С помощью купонов, исследований и планирования питания, она откладывает от \$200 до \$250 в месяц. Она сказала мне: «Это деньги на колледж. Это на отпуск.»

The Wall Street Journal написал то же самое в статье 2011 года, озаглавленной «Магазинные продажи начинаются дома»:

Хорошо известно, что покупатели изучают дорогостоящие товары, как например әлектронику, с помощью Интернет, однако с выходом из рецессии потребители также начинают скурпулёзно исследовать через Интернет и товары ежедневного применения, такие как салфетки и моющие средства. Более пятой части из них также изучают продукты питания и напитки, почти треть исследует продукты для домашних животных и 39\% смотрят на товары для детей. ${ }^{6}$

Согласно той же статье, сегодня 62\% покупателей отмечают, что они ищут варианты покупки через Интернет по крайней мере в половине случаев перед походом в магазин.

В этих историях два героя: покупатель, который проводит исследования, и менеджер магазина или маркетолог, которые достаточно умны, чтобы находиться на месте в тот момент, когда покупатель их ищет.

Как говорит Ришад Тобаковала из VivaKi: «Не называйте их поисковыми машинами. Называйте их связующими машинами.» 
Глава 3: ZMOT везде вокруг нас 
OF MOT RATINGS \& REVIEWS: WORD OF MOT RATINGS \& REVIEWS: WORD OF MOT R VS: WORD OF MOT RATINGS \& REVIEWS: WORD OF MOT RATINGS \& REVIEWS: WORL REVIEWS: WORD OF MOT RATINGS \& REVIEWS: WORD OF MOT RATINGS \& REVIEV iS \& REVIEWS: WORD OF MOT RATINGS \& REVIEWS: WORD OF MOT RATINGS \& RE ITINGS \& REVIEWS: WORD OF MOT RATINGS \& REVIEWS: WORD OF MOT RATINGS DF MOT RATINGS \& REVIEWS: WORD OF MOT RATINGS \& REVIEWS: WORD OF MC S: WORD OF MOT RATINGS \& REVIEWS: WORD OF MOT RATINGS \& REVIEWS: WOI REVIEWS: WORD OF MOT RATINGS \& REVIEWS: WORD OF MOT RATINGS \& REVIEW TINGS \& REVIEWS: WORD OF MOT RATINGS \& REVIEWS: WORD OF MOT RATINGS OF MOT RATINGS \& REVIEWS: WORD OF MOT RATINGS \& REVIEWS: WORD OF MOT S: WORD OF MOT RATINGS \& REVIEWS: WORD OF MOT RATINGS \& REVIEWS: WORI REVIEWS: WORD OF MOT RATINGS \& REVIEWS: WORD OF MOT RATINGS \& REVIEWS ATINGS \& REVIEWS: WORD OF MOT RATINGS \& REVIEWS: WORD OF MOT RATINGS \& I T RATINGS \& REVIEWS: WORD OF MOT RATINGS \& REVIEWS: WORD OF MOT RATINGS OF MOT RATINGS \& REVIEWS: WORD OF MOT RATINGS \& REVIEWS: WORD OF MOT $\mathbf{R}$ VS: WORD OF MOT RATINGS \& REVIEWS: WORD OF MOT RATINGS \& REVIEWS: WORL REVIEWS: WORD OF MOT RATINGS \& REVIEWS: WORD OF MOT RATINGS \& REVIEV IS \& REVIEWS: WORD OF MOT RATINGS \& REVIEWS: WORD OF MOT RATINGS \& RE ITINGS \& REVIEWS: WORD OF MOT RATINGS \& REVIEWS: WORD OF MOT RATINGS DF MOT RATINGS \& REVIEWS: WORD OF MOT RATINGS \& REVIEWS: WORD OF MC S: WORD OF MOT RATINGS \& REVIEWS: WORD OF MOT RATINGS \& REVIEWS: WOI REVIEWS: WORD OF MOT RATINGS \& REVIEWS: WORD OF MOT RATINGS \& REVIEV TINGS \& REVIEWS: WORD OF MOT RATINGS \& REVIEWS: WORD OF MOT RATINGS OF MOT RATINGS \& REVIEWS: WORD OF MOT RATINGS \& REVIEWS: WORD OF MOT S: WORD OF MOT RATINGS \& REVIEWS: WORD OF MOT RATINGS \& REVIEWS: WORI REVIEWS: WORD OF MOT RATINGS \& REVIEWS: WORD OF MOT RATINGS \& REVIEWS ATINGS \& REVIEWS: WORD OF MOT RATINGS \& REVIEWS: WORD OF MOT RATINGS \& I T RATINGS \& REVIEWS: WORD OF MOT RATINGS \& REVIEWS: WORD OF MOT RATINGS OF MOT RATINGS \& REVIEWS: WORD OF MOT RATINGS \& REVIEWS: WORD OF MOT $\mathbf{R}$ VS: WORD OF MOT RATINGS \& REVIEWS: WORD OF MOT RATINGS \& REVIEWS: WORL REVIEWS: WORD OF MOT RATINGS \& REVIEWS: WORD OF MOT RATINGS \& REVIEV IS \& REVIEWS: WORD OF MOT RATINGS \& REVIEWS: WORD OF MOT RATINGS \& RE ITINGS \& REVIEWS: WORD OF MOT RATINGS \& REVIEWS: WORD OF MOT RATINGS DF MOT RATINGS \& REVIEWS: WORD OF MOT RATINGS \& REVIEWS: WORD OF MC S: WORD OF MOT RATINGS \& REVIEWS: WORD OF MOT RATINGS \& REVIEWS: WOI REVIEWS: WORD OF MOT RATINGS \& REVIEWS: WORD OF MOT RATINGS \& REVIEW TINGS \& REVIEWS: WORD OF MOT RATINGS \& REVIEWS: WORD OF MOT RATINGS OF MOT RATINGS \& REVIEWS: WORD OF MOT RATINGS \& REVIEWS: WORD OF MOT S: WORD OF MOT RATINGS \& REVIEWS: WORD OF MOT RATINGS \& REVIEWS: WORI REVIEWS: WORD OF MOT RATINGS \& REVIEWS: WORD OF MOT RATINGS \& REVIEWS ATINGS \& REVIEWS: WORD OF MOT RATINGS \& REVIEWS: WORD OF MOT RATINGS \& I T RATINGS \& REVIEWS: WORD OF MOT RATINGS \& REVIEWS: WORD OF MOT RATINGS OF MOT RATINGS \& REVIEWS: WORD OF MOT RATINGS \& REVIEWS: WORD OF MOT R VS: WORD OF MOT RATINGS \& REVIEWS: WORD OF MOT RATINGS \& REVIEWS: WORI 


\section{ГЛ А B A \\ 4}

\section{РЕЙТИНГИИ О т 3 ЫВ Ы: И 3 У $С$ T $B$ MOT}

«Впервые в истории передаваемая из уст в уста информациия перешла в изифровую форм⿻.»

- Бретт Xарт

ОСНОватеЛЬ И СЕO BAZAARVOICE

Взрывное распространение он^айнрейтингов и отзывов изменило способ получения информации. ОАнако это изменение по-прежнему основано на оАной из Аревнейших человеческих особенностей: передаче информации из уст в уста.

«Передача информации из уст в уста - это механизм, который мы используем со времён появления племён для обмена необходимыми знаниями», говорит Бретт Харт из Bazaarvoice. «Где можно хорошо поохотиться? Где можно хорошо порыбачить? Как не быть съеденным саблезубым тигром?»

Сегодняшние представители племён не говорят о тиграх - они говорят о вашей продукции, каждый день, на десятках сайтов, о которых вы слышали, и на тысячах сайтов, о которых вы ничего не знаете. В сети есть рейтинги, отзывы и обсуждения относительно любого нового моющего средства, мультивитаминов или Снагги (Примечание переводчика: Snuggy - плед с рукавами, брэнд приобрёл известность в США в конце 2008 - начале 2009 годов), которые продаются в вашей местной аптеке (Примечание переводчика: речь в книге идёт про США, где в аптеках продают не только лекарства, но также продукты питания, одежду, товары повседневного спроса и пр.) Возьмите любой университет страны, и вы сможете узнать, кто является в нём лучшим преподавателем истории. «Месопотамия 401 с профессором Дженни» - это хороший курс, или полная ерунда? Вы узнаете с помощью ZMOT. Решения принимаются здесь.

Как выглядит онлайн-процесс передачи информации из уст в уста?

- Потребители общаются между собой напрямую посредством электронной почты, через социальные сети, чаты и системы мгновенных сообщений, или размещают видео на YouTube и других сайтах

- Отзывы на таких сайтах, как Epinions, TripAdvisor, DealerRater и Yelp

- Комментарии и рейтинги, которые появляются для компаний в таких приложениях, как Google Maps

- Форумы на корпоративных и ритейловых сайтах всех возможных видов

- Сайты по интересам, на которых мамы, игроки в гольф, шеф-повара или скейтбордисты обмениваются мнениями и информацией

- Рейтинги продавцов в результатах поиска (наберите в Google "kids bikes" и вы увидите звёздочки) (Примечание переводчика: не работает в русской версии Google). 
Однако существует одно важное различие между передачей информации из уст в уста в прошлом и сейчас, в цифровой среде. «Разговор за оградой ведётся один к одному», говорит профессор Дэйв Рэйбштейн из The Wharton School. «Разговор онлайн - один к миллионам. Если у вас есть положительный опыт, вы делитесь им, другие люди распространяют его дальше, миллионам получателей. Вы оставляете запись - и неожиданно она разлетается повсюду.»

$$
* * *
$$

Аудитория задаёт три вопроса о вашей продукции:

- Позволит ли она сэкономить мне деньги?

- Позволит ли она сэкономить мне время?

- Улучшит ли она мою жизнь?

Когда люди спрашивают друг друга о вашей продукции во время ZMOT, можете быть уверены, они будут говорить об одной из этих трёх вещей.

Возможно, у них уже есть общее представление о том, что они хотят. «Я знаю, что новый телевизор будет стоить около $\$ 500$. У меня есть $\$ 500$. Я просто хочу быть уверен в том, что покупаю самый лучший телевизор за эти деньги.»

И можете быть уверены - они будут близки к тому, чтобы принять решение. Вот почему в конце-концов они стоят в проходе магазина, набирая что-то на своём телефоне. Рейтинги и отзывы являются маленькими указателями, оставленными лицами, принимающими решения, для других лиц, принимающих решения. Люди, которые читают их, не просто болтаются вокруг. Это люди, которые планируют совершить покупку.

$$
* * *
$$

СЕО и СМО обычно нервничают по поводу онлайн рейтингов и комментариев - особенно если нужно открыть возможность оставлять комментарии на их собственных сайтах. Что, если кто-нибудь скажет что-то отрицательное? Что, если все они сделают это?

Я отвечу так - расслабътесь. И вот почему:

Бодышинство отзывов явдяются подожитедыными. «Мы выяснили, что в среднем по всему земному шару оценка товаров составляет 4.3 из 5.0", говорит Бретт Харт из Bazaarvoice. Его компания предоставляет услуги по взаимодействию с потребителями корпорациям, начиная от Wall-Mart и заканчивая Johnson \& Johnson. Согласно Бретту, 80\% всех онлайн-отзывов составляют четырёх- или пятизвёздочные.

Больше того: «Мы нашли новую версию правила 80-20: 80\% всех отзывов на сайте некоторого ритейлера пишут $20 \%$ его лучших потребителей, если считать совокупное потребление за всё время. Мы называем их супер-покупателями.»

Математика достаточно простая: люди больше всего любят говорить о товарах, которые они любят больше всего.

Пдохие отзывы не все такие плохие. «Люди до смерти напуганы тем, что не все комментарии могут быть положительными», говорит Дэйв Рэйбштейн. «Однако отрицательные комментарии добавляют подлинность.»

Бретт Харт произносит это иначе: «Боязнь отрицательного - это то, что по-прежнему сдерживает распространение Нулевого Момента Истины. Мы особенно сильно замечаем этот страх в случае стоматологов или агентов по продаже недвижимости, то есть в бизнесе, который основан больше на человеческих отношениях, чем на продаже товаров. 
Однако истина состоит в том, что отрицательные отзывы увеличивают обменные курсы любого бизнеса, потому что люди видят их и знают, что они совершают покупки в честной среде.»

Одно дело, если вы производите действительно ужасный продукт. Но если ваш продукт является качественным (а он несомненно является таковым), то вам не следует бояться редких отрицательных отзывов.

Разговор уже идёт. Прямо сейчас, в этот самый момент, люди обсуждают ваш продукт онлайн. Вы не можете запустить или остановить это. Вы можете сделать выбор не участвовать в этом разговоре, но это на самом деле будет выглядеть, как запихивание своей головы в песок ровно в то время, когда со стороны подбегает конкурент, чтобы переманить ваших покупателей. Лучше приветствовать этот разговор и быть его частью. Как отмечает Бретт Харт, «Передача информации из уст в уста должна стать частью центральной нервной системы любой компании.»

$$
* * *
$$

Почему люди должны принимать решения, основываясь на мнениях незнакомцев? Они не делают этого. Они принимают решения, основываясь на мнении людей, таких же как они сами. Которых они находят во время ZMOT.

«Это тот образ мышления, который я использую, будучи онлайн», говорит Тина Шарки, Председатель и Всемирный Президент BabyCenter. «На нашем сайте мы видим родителей, которые спрашивают: 'Мой ребёнок только что потерял первый зуб. Сколько сейчас стоит вызов Зубной Феи? Когда стоит рассказать правду про Зубную Фею? Как это сделать?'»

Вы обнаружите, что то же самое происходит как в случае Зубной Феи, так и в случае бухгалтерской программы для двадцатитысячной компании. Люди ищут тех, кто уже был в той же самой ситуации, в которой они находятся сейчас. Они знают, что их коллеги-потребители (в отличие от рекламодателей) не пытаются продать им что-нибудь.

Наше исследование ZMOT 2011 года показало, что 37\% покупателей называют онлайн социальные источники, как оказывающие влияние в процессе принятия решений. Эта цифра выросла с 19\% в 2010 году - почти вдвое за год. Наиболее важные онлайн социальные активности среди покупателей:

- Получение онлайн-рекомендации от друга

- Превращение в друга или последователя брэнда

- $\quad$ Чтение блогов, где обсуждается продукт

- Просмотр упомянутого брэнда на сайте социальной сети, такой как Facebook

Люди испытывают сильное желание поделиться знаниями, когда они достигают собственного «момента мастерства», как называет это Тина Шарки. «Эта мама, у которой есть ребёнок с определённым типом аллергии, она теперь знает, как с ней бороться. И она хочет поделиться этим знанием. Она прошла через это, она самостоятельно получила знания, и теперь она действительно хочет помочь и поддержать других.»

Большинство из нас обладает эмпатией в отношении людей, которые находятся прямо позади нас, которые делают то же самое. И если мы можем облегчить им жизнь, мы делаем это. Как в старой поговорке: «Если бы только я знал тогда то, что знаю сейчас.» 
Правда заключается в том, что для многих покупателей во многих категориях единственным наиболее сильным стимулом для покупки является чья-то рекомендация.

Google настолько убеждены в этом, что мы создали кнопку +1 , которая позволяет любому в один клик рекомендовать товары, услуги и вебсайты друзьям. Глядя на вебсайт, или даже на результаты поиска, вы нажимаете кнопку «+1», чтобы сказать друзьям, «это мне нравится.» В следующий раз, когда ваши друзья будут осуществлять поиск, они увидят вашу рекомендацию под результатом поиска для этой страницы. Вы станете частью их ZMOT.

Особая ценность может быть создана, если таким образом объединить поиск и социальную среду. Это классическое сообщение из уст в уста, например, вопрос друзьям, посещали ли они гору Рашмор, или знают ли они хорошее место, где можно остановиться на озере Тахо.

\section{Рисунок 4-1: Пример кнопки Google + 1 в результатах поиска}

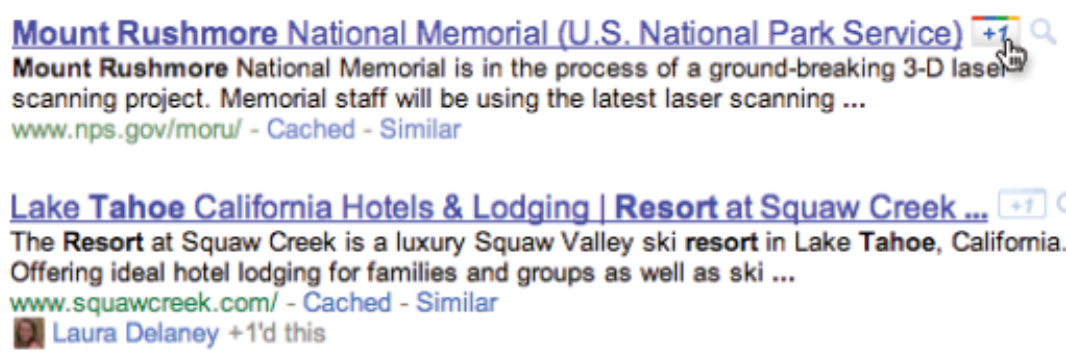

Source: +1 as illustrated on the Google Official Google Blog on 3/30/11

Но это такое сообщение из уст в уста, которое вы можете найти именно в тот момент, когда вы в нём нуждаетесь. Вам не нужно прочёсывать свой почтовый ящик или надеяться, что вы найдёте нужного друга в правильный момент. Если я ищу гостиницу через Интернет и шестеро моих друзей дали ей «+1», моё решение принято.

$$
\text { * * * }
$$

Позвольте мне сделать ещё одно замечание насчёт онлайн рейтингов и отзывов: они являются потрясающим ресурсом для покупателей, но они также являются потрясающим ресурсом и для бизнеса.

«Для брэндов ZMOT явяется невероятным источником понимания, насколько удовлетворены их потребители, в реальном времени», говорит Бретт Харт.

«Вы можете видеть, что люди говорят друг другу о вашем продукте каждый день, что полностью отличается от маркетинговых опросов. Это как если бы я пришёл в маркетинговое агентство и сказал - 'я не хочу спрашивать случайных людей о том, что они думают о моей продукции; я хотел бы спросить людей, которые хотели бы поговорить о ней и выразить чёткое мнение.'»

«Фокус-группы являются искуственными. Людям платят за то, что они там находятся. Они знают о том, что за стеклом стоят люди из агентства и наблюдают за ними», говорит он. «Единственное, что является чистым и достоверным на тему происходящего на рынке в реальности, это то, как люди разговаривают друг с другом.» 
«Для бизнеса ZMOT эволюционировал от простого - 'мне нужно увеличить мои онлайн продажи', к целостному подходу - 'О боже, вообще-то я могу быть информирован о маркетинге и мерчандайзинге лучше чем когда-либо.' Наблюдательный менеджер по продукту может точно определить, почему они получают высокий коэффициэнт возврата или почему они получают высокие продажи.»

Механизм, который позволяет вам в точности узнавать, о чём думают ваши потребители в процессе принятия решения? Который показывает, что они хотят от вас и в чём нуждаются? И даже позволяет вам ответить им, если вы хотите? Какая интересная идея.

За исключением того, что это больше не идея - это то, как люди обмениваются информацией сегодня в процессе ZMOT. 
EOUAL THOUGHT, NOT AFTERTHOUGHT EQUAL THOUG IT EQUAL THOUGHT IOT AFTERTHOUGHT EQUAL. THOUGHT, NOT AFTERTHOUGHT EQU. ERTHOUGHT EQUAL THOUGHT, NOT AFTERTHOUGHT EQUAL THOUGHT, NOT AFTERTHC HT, NOT AFTERTHOUGHT EQUAL THOUGHT, NOT AFTERTHOUGHT EQUAL THOUGHT, N HOUGHT, NOT AFTERTHOUGHT EQUAL THOUGHT, NOT AFTERTHOUGHT RTHOUGHT EQUAL THOUGHT, NOT AFTERTHOUGHT

NOT AFTERTHOUGHT EQUAL THOUGHT, NOT AFTERTHOUGHT EQUAL THOUGHT, TEQUAL THOUGHT, NOT AFTERTHOUGHT EQUAL THOUGHT, NOT AFTERTHOUGHT EC RTHOUGHT EQUAL THOUGHT, NOT AFTERTHOUGHT EQUAL THOUGHT, NOT AFTERTH

VOT AFTERTHOUGHT EQUAL THOUGHT, NOT AFTERTHOUGHT EQUAL. THOUGHT, NO AT EQUAL THOUGHT, NOT AFTERTHOUGHT EQUAL. THOUGHT, NOT AFTERTHOUGHT EQU. ERTHOUGHT EQUAL THOUGHT, NOT AFTERTHOUGHT EQUAL THOUGHT, NOT AFTERTH AT, NOT AFTERTHOUGHT EQUAL THOUGHT, NOT AFTERTHOUGHT EQUAL. THOUGHT, $N$ HOUGHT, NOT AFTERTHOUGHT EQUAL THOUGHT, NOT AFTERTHOUGHT EQUAL THC EQUAL THOUGHT, NOT AFTERTHOUGHT EQUAL THOUGHT, NOT AFTERTHOUGHT I RTHOUGHT EQUAL THOUGHT, NOT AFTERTHOUGHT EQUAL THOUGHT, NOT AFTER NOT AFTERTHOUGHT EQUAL THOUGHT, NOT AFTERTHOUGHT EQUAL THOUGHT, EQUAL THOUGHT, NOT AFTERTHOUGHT EQUAL THOUGHT, NOT AFTERTHOUGHT EC RTHOUGHT EQUAL THOUGHT, NOT AFTERTHOUGHT EQUAL THOUGHT, NOT AFTERTH I AFTERTHOUGHT EQUAL THOUGHT, NOT AFTERTHOUGHT EQUAL THOUGHT, NO IT EQUAL THOUGHT, NOT AFTERTHOUGHT EQUAL. THOUGHT, NOT AFTERTHOUGHT EQU. ERTHOUGHT EQUAL THOUGHT, NOT AFTERTHOUGHT EQUAL THOUGHT, NOT AFTERTHC AT, NOT AFTERTHOUGHT EQUAL THOUGHT, NOT AFTERTHOUGHT EQUAL THOUGHT, N HOUGHT, NOT AFTERTHOUGHT EQUAL THOUGHT, NOT AFTERTHOUGHT EQUAL THC EQUAL THOUGHT, NOT AFTERTHOUGHT EQUAL THOUGHT, NOT AFTERTHOUGHT RTHOUGHT EQUAL THOUGHT, NOT AFTERTHOUGHT EQUAL THOUGHT, NOT AFTER NOT AFTERTHOUGHT EQUAL THOUGHT, NOT AFTERTHOUGHT EQUAL THOUGHT, EQUAL THOUGHT, NOT AFTERTHOUGHT EQUAL THOUGHT, NOT AFTERTHOUGHT EC ETHOUGHT EQUAL THOUGHT, NOT AFTERTHOUGHT EQUAL THOUGHT, NOT AFTERTH NOT AFTERTHOUGHT EQUAL THOUGHT, NOT AFTERTHOUGHT EQUAL THOUGHT, NO IT EQUAL THOUGHT, NOT AFTERTHOUGHT EQUAL. THOUGHT, NOT AFTERTHOUGHT EQU, ERTHOUGHT EQUAL THOUGHT, NOT AFTERTHOUGHT EQUAL THOUGHT, NOT AFTERTH HT, NOT AFTERTHOUGHT EQUAL THOUGHT, NOT AFTERTHOUGHT EQUAL THOUGHT, N HOUGHT, NOT AFTERTHOUGHT EQUAL THOUGHT, NOT AFTERTHOUGHT EQUAL THC EQUAL THOUGHT, NOT AFTERTHOUGH RTHOUGHT EQUAL THOUGHT, NOT AFTERTHOUGHT NOT AFTERTHOUGHT EQUAL THOUGHT, NOT AFTERTHOUGHT EQUAL THOUGHT, I TEQUAL THOUGHT, NOT AFTERTHOUGHT EQUAL THOUGHT, NOT AFTERTHOUGHT EC RTHOUGHT EQUAL THOUGHT, NOT AFTERTHOUGHT EQUAL THOUGHT, NOT AFTERTH EQUAL. THOUGHT, NOT AFTERTHOUGHT EQUAL THOUGHT, NO IT EQUAL THOUGHT, NOT AFTERTHOUGHT EQUAL. THOUGHT, NOT AFTERTHOUGHT EQU, ERTHOUGHT EQUAL THOUGHT, NOT AFTERTHOUGHT EQUAL THOUGHT, NOT AFTERTHS 4 T, NOT AFTERTHOUGHT EQUAL THOUGHT, NOT AFTERTHOUGHT EQUAL THOUGHT, N 


\section{ГЛ А B A}

5

\section{BНИМАНИЕ НАРАВНE С ОСТААЬНЫМИ, А НЕ В ПОСЛЕДНЮЮ ОЧЕРЕДЬ}

«Мы являемся свидетелями изменений, которые происходят с беспрецедентной скоростью. Если раньше серьёзные инновации, способные изменить наш жизненньии уклад, происходили один или два раза в течение жизни одного поколения, то теперь это происходит почти ежегодно.

Поэтому задачей номер один для всех маркетологов, неважно, насколько развит их брэнд, является оставаться по-прежнему значимыми для своих потребителей.

Мы должны думать о том, как меняется жизнь наших конечных пользователей, вне зависимости от того, является ли конечный пользователь потребителем, пациентом, врачом, или кем-либо ещё. Чтобы оставаться значимыми, мы должны быть частью их новой экосистемы.»

- КИМ КАДЛЕК

ВИЦЕ-ПРЕЗИДЕНТ, ГЛОБАЛЬНАЯ ГРУППА МАРКЕТИНГА JOHNSON \& JOHNSON

Если бы меня попросили назвать оАну самую важную вещь, которую вы Аолжны вынести из этой книги, то это бы^о бы: ZMOT нужно УАелять внимание наравне с остальными, а не в послеАнюю очереАь.

Помните акробатов, которые крутят тарелки в цирке? Если вы - владелец бизнеса или брэнд менеджер, то у вас должны всё время крутиться три тарелки: стимул, полка и опыт.

Я здесь чтобы сказать вам, что ZMOT - это четвёртая тарелка. Она настолько же важна, как и три другие. И на самом деле, она может помочь вам удержать три другие тарелки в воздухе.

Мы всё время слышим возражения насчёт ZMOT. Позвольте мне поделиться с вами некоторыми из них.

«Никто не ищет в Интернет зубную пасту или скрепки для бумаги.»

В самом деле? Скажите это 3М. В течение первого года после того, как они начали принимать на своём сайте комментарии о скотче, они получили почти 3000 отзывов от своих потребителей. 
Например, такой отзыв:

Я использую эту ленту всё вреля, потому что она удерживает те вещци, которые мне нужны, вместе, оставаясь невидимой. Я использовал этот продукт в течение многих лет и буду продолжать использовать его и дальще.

Да, люди находят время, чтобы оставить комментарии онлайн о том, насколько они любят скотч.

Это происходит потому, что усилие стремится к нулю. Вы бы никогда не сели в свою машину, не поехали бы в библиотеку и не стали бы подниматься на второй этаж и просить сонного библиотекаря принести отчёты Consumer Reports перед тем, как купить шариковую ручку за 39 центов. Усилие непропорционально вещи. Однако сегодня нет таких трудностей. Вы можете вытащить свой мобильный телефон и посмотреть - или оставить своё мнение - на лету.

Когда я делаю презентацию, например, в Хилтоне, я говорю аудитории: «Вы найдёте онлайн больше отзывов о продукте Baunce Dryer Bar, чем о гостинице, в которой мы сейчас находимся.» Это всегда поражает людей, и всегда оказывается правдой.

ZMOT - это не только про отпуска, машины и холодильники. Это и про шампунь против перхоти за \$5.99, и пачку крупы за \$3.29, и ручку за 39 центов. Люди любят изучать и делиться мнением обо всех товарах, которые они используют. Поверьте мне, ваш замечательный продукт - не исключение. Потребители научились применять стратегии, которые они используют для покупки автомобилей, к повседневным вещам.

\section{«Это неприменимо в моей отрасли.»}

Классическое возражение.

Бет Комсток, старший вице-президент и директор по маркетингу в General Electric, имеет довольно интересную точку зрения по этому поводу, поскольку GE производит всё, начиная от лампочек и заканчивая реактивными двигателями. Она говорит:

Может быть, если вы производите локомотивы, или програлминое обеспечение для автоматизации производственных линий, вы думаете: Зачем мне размещцать видео или веб-страницьв? Кто будет их использовать? Однажды на нашей маркетинговой встрече мы решили поискать на Үоитиве иленно эти вещц. И знаете, что выяснилось? Мы нашли сотни видео, включая видео наших конкурентов, на такие темы, как интеллектуальный подход к автоматизации производственных линий. Это было большим открытием. Я думаю, что ми могли бы задать любую тему и обнаружить то же самое.

Мы увидели достаточно данных, чтобы понять, что руководители само$2 о$ высокого уровня самостоятельно производят поиск в Интернет ещё до того, как они встретлтся с потенцииальным поставщиком. Покупаете ли вы холодильник или реактивный двигатель, вы хотите сделать свою домашнюю работу заранее.

Если вас нельзя найти онлайн в тот момент, когда они делают свою домашнюю работу, поверьте, они найдут других. Вот что сказал CEO BestBuy Брайан Данн сайту RetailGeek.com в 2011 году: 
«Мы знаем, что 60\% наших магазинных продаж в США происходят благодаря посещению сайта BestBuy.com».

Этот процент не является необычным. Цифры велики для напитков, школьных принадлежностей и других товаров, которые вы не станете покупать онлайн.

Если вы - местная пиццерия или магазин электроники, доступность во время ZMOT для вас является ещё более важной. Это то, куда люди идут, чтобы найти вас сегодня. Вас может удивить, если вы узнаете, что 20\% поисковых запросов по всем ресурсам Google являются местными. Это ещё не всё - цифра удваивается до 40\% для мобильных запросов. ${ }^{1}$

Недавно мы провели тест среди четырёх крупных брэндов продуктов питания совместно с нашим исследовательским партнёром SymphonyIRI. Для каждого брэнда мы выбрали тестовый рынок, где мы не показывали рекламу в результатах поиска. На другом аналогичном рынке, с равными условиями, мы включали рекламу. Результаты? На рынках, где потребители могли видеть поисковую рекламу, объём магазинных продаж увеличился на $3.1 \% .^{2}$ Рост на $3.1 \%$ в категории, которая обычно является плоской!

Определённо ZMOT действует не только в категории продуктов питания и потребительских товаров. Опрос Shopper Sciences показал, насколько широко распространён ZMOT по всем категориям, в которых покупатели принимают решения:

\section{Рисунок 5-1: Таблица по категориям}

\begin{tabular}{|l|c|c|c|}
\hline \multicolumn{1}{|c|}{ Category Purchased } & $\begin{array}{c}\text { Number of } \\
\text { sources used } \\
\text { by the typical } \\
\text { shopper }\end{array}$ & $\begin{array}{c}\text { Average } \\
\text { usage across } \\
\text { sources }\end{array}$ & $\begin{array}{c}\% \text { of } \\
\text { shoppers } \\
\text { influenced at } \\
\text { ZMOT }\end{array}$ \\
\hline Automotive & 18.2 & $34 \%$ & $97 \%$ \\
\hline Technology (Consumer Electrionics) & 14.8 & $30 \%$ & $92 \%$ \\
\hline Voters & 14.7 & $35 \%$ & $95 \%$ \\
\hline Travel & 10.2 & $22 \%$ & $99 \%$ \\
\hline Over-the-Counter Health & 9.8 & $18 \%$ & $78 \%$ \\
\hline Consumer Packaged Goods: Grocery & 7.3 & $15 \%$ & $61 \%$ \\
\hline Consumer Packaged Goods: & 7 & $14 \%$ & $63 \%$ \\
\hline Health/Beauty/Personal Care & 5.8 & $12 \%$ & $72 \%$ \\
\hline Quick-Serve Restaurants & 10.8 & $25 \%$ & $91 \%$ \\
\hline Banking & 11.7 & $26 \%$ & $94 \%$ \\
\hline Insurance & 8.6 & $19 \%$ & $81 \%$ \\
\hline Credit Card & 8.9 & $20 \%$ & $89 \%$ \\
\hline Investments & & $15 \%$ & \\
\hline
\end{tabular}

Source: Google/Shopper Sciences, Zero Moment of Truth Industry Studies, U.S., April 2011

Sample sizes for each category noted in appendix Figure A-10. 
Когда влиянию подвержены 95\% голосующих и 99\% путешественников, я думаю, можно смело сказать, что ZMOT действует во всех отраслях.

\section{«Матери слишком заняты. У них нет времени на эти вещи.»}

Это я слышу достаточно часто. Мой ответ: вы шутите? Матери обладают чёрными поясами по ZMOT! Сегодняшние матери и отцы слишком заняты и ограничены бюджетом, поэтому они идут онлайн в поисках решения. У кого есть время стоять в проходе напротив слеллажа с витаминами и читать этикетки с обратной стороны, чтобы найти нужные? Сегодняшние мамы ищут рецепты онлайн, они сравнивают цены в поисках более дешёвых брэндов, они смотрят рекомендации друзей.

Марк Аддикс, старший вице-президент и директор по маркетингу General Mills, отмечает: Мы видим определённые периоды в течение дня, когда потребители приходят на наши сайты - когда они буквально пытаются выяснить, «Что сегодня приготовить на ужин?» Матери начинают прибывать в магазинь прилерно в четьре часа. Наша исследовательскал команда находилась в супермаркетах и наблюдала этот процесс. Матери идут прямо к мясной секции - «я знаю, что мне нужна говядина» - и здесь они достают телефон и начинают смотреть онлайн. Они смотрят рецепть, или смотрят на экономичную упаковку и думают, 'Что ещё я могу приготовить на этой неделе из рублёного мяса?'

Тина Шарки из BabyCenter утверждает, что матери с большей вероятностью пойдут онлайн, чем кто-либо ещё.

Когда мы изучали точки перегиба в жизни женщины, когда она может начать использовать социальные носители, и начинает использовать социальные среды более активно, то становление матерью значительно перевесило любые другие события в жизни. Женщины обладают глубокими привычками делиться: отзывы о товарах, статьи, которые они пересылают, разговоры, форумы, участие и поддержка всеми возможными способами.

Безусловно, много лет назад домохозяйки возможно ждали бы приходящие раз в месяц по почте журналы, и это было бы тем способом, каким они получали бы сообщения от рекламодателей. Однако сейчас они у власти, и это происходит минута за минутой, а не месяц за месяцом. Они начинают разговор с рекламодателем, когда готовы к этому.

«У нас уже есть вебсайт. У нас всё хорошо.»

Это напоминает мне ситуацию десятилетней давности, когда некоторым маркетологам приходилось воевать с СЕО, чтобы убедить их в необходимости иметь в первую очередь свой сайт. Оказывается, вебсайт - довольно полезная штука.

«Успешный бизнес - это организация, которую сложнее всего изменить», любит говорить профессор Джерри Винд. Сейчас мир снова меняется, и ваш успешный бизнес тоже должен измениться. 
Это утверждение справедливо и для многомиллионной компании, и для местного кафе. «Если бы мы не воспользовались ZMOT, мы бы не существовали сегодня, как бизнес», говорит Мария Баух. Магазин, совладельцем которого она является, Butter Lane Cupcakes, изготавливает и продаёт изумительные кексы в Нью-Йорке. «На самом деле у нас просто нет возможности преуспеть, если мы положимся только на проходящих мимо наружней витрины нашего единственного магазина.

«Мы спрашиваем у людей, как они находят Butter Lane Cupcakes - множество людей находит нас на Yelp, множество людей находят нас с помощью Google AdWords, есть масса блоггеров, масса людей, которые находятся в онлайн. Это как встроенный маркетинг и встроенная база потребителей.»

Она добавляет, «Мы регулярно перестраиваемся в зависимости от отзывов покупателей. Мы решили, что должны приветствовать посетителей в течение пяти или десяти секунд после того, как они открыли дверь. И это то, что мы выяснили, просто слушая, что люди про нас говорили.

«Это не просто милая вещь, которой можно воспользоваться по желанию, если вы хотите. Это абсолютно необходимая вещь, в частности, для бутикового бизнеса.»

$$
* * *
$$

Давайте вернёмся к данным Shopper Sciences, которые я привёл ранее:

Рисунок 5-2: Использованные источники по типам

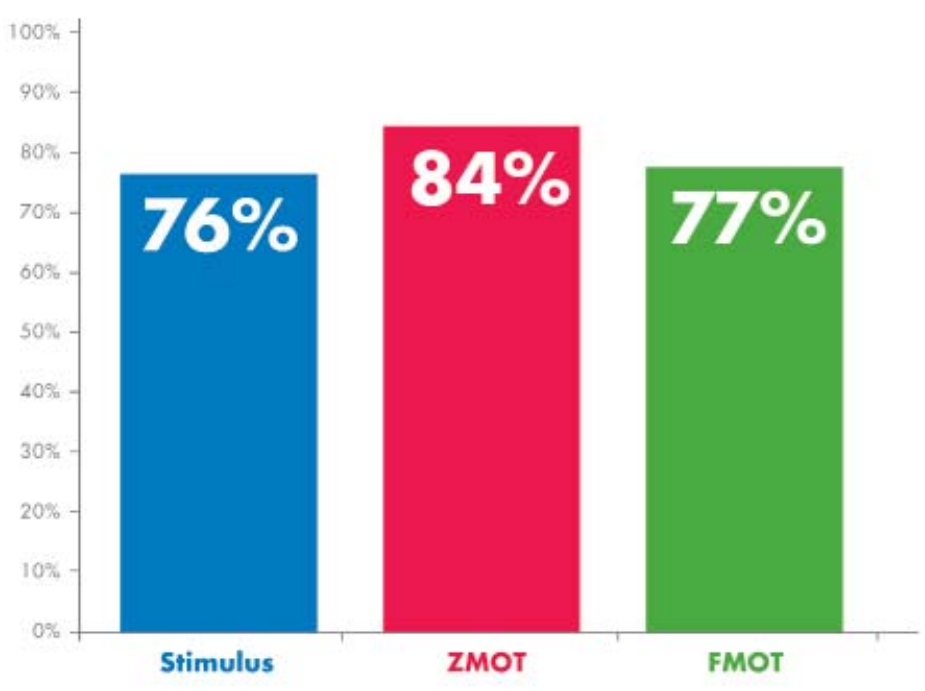

Q2 When you were considering purchasing [PRODUCT] what sources of information did you seek out to help with your decision?

Base $\mathrm{N}=5,003$

Source: Google/Shopper Sciences, Zero Moment of Truth Macro Study, U.S., April 2011 
Вот что я имею в виду, когда говорю о внимании наравне с остальными. Покупатели сегодня используют ZMOT источники наравне с классическим стимулом и FMOT источниками. Ни один из трёх не уходит в сторону. Чем больше информации доступно, тем больше покупатель ищет. Это самоподдерживающийся процесс.

$$
* * *
$$

Вы бы никогда не организовали номер 8-800, на звонки которого никто бы не отвечал. (Правда?) Вы бы не поставили такой номер, позволив ему просто звонить.

Интернет является таким номером 8-800, и он был настроен для вас, даже если вы об этом и не просили.

Люди «звонят» вам своими поисковыми запросами каждую минуту, каждый день. Бабушка теперь не звонит по номеру 1-800-Butterball, она ищет в Интернет, «как узнать, что индейка готова?» Если индейка - ваш бизнес, вам лучше бы быть там с полезным ответом (или демо, или купоном, или рецептом). Если люди ищут ваш продукт, а вы не отвечаете на эти поиски, то кто ответит - как вы думаете?

Поэтому я спрашиваю людей: У вас есть план победы в Нулевой Момент Истины, который настолько же хорош, как план стимула, план полки и план вашего продукта? Или ваш план надежда на то, что всё будет хорошо? Но надежда - это не план!

Давайте теперь поговорим о том, как заставить тарелку ZMOT крутиться и выигрывать. 
Глава 5: Внимание наравне с остальными, а не в последнюю очередь 
AT ZMOT HOW TO WIN AT ZMOT HOW TO WIN AT ZMOT HOW TO WIN AT ZMOT H HOW TO WIN AT ZMOT HOW TO WIN AT ZMOT HOW TO WIN AT ZMOT HOW TO V AT ZMOT HOW TO WIN AT ZMOT HOW TO WIN AT ZMOT HOW TO WIN AT ZMOT H HOW TO WIN AT ZMOT HOW TO WIN AT ZMOT HOW TO WIN AT ZMOT HOW TO V AT ZMOT HOW TO WIN AT ZMOT HOW TO WIN AT ZMOT HOW TO WIN AT ZMOT H HOW TO WIN AT ZMOT HOW TO WIN AT ZMOT HOW TO WIN AT ZMOT HOW TO V AT ZMOT HOW TO WIN AT ZMOT HOW TO WIN AT ZMOT HOW TO WIN AT ZMOT H HOW TO WIN AT ZMOT HOW TO WIN AT ZMOT HOW TO WIN AT ZMOT HOW TO V AT ZMOT HOW TO WIN AT ZMOT HOW TO WIN AT ZMOT HOW TO WIN AT ZMOT H HOW TO WIN AT ZMOT HOW TO WIN AT ZMOT HOW TO WIN AT ZMOT HOW TO V AT ZMOT HOW TO WIN AT ZMOT HOW TO WIN AT ZMOT HOW TO WIN AT ZMOT H HOW TO WIN AT ZMOT HOW TO WIN AT ZMOT HOW TO WIN AT ZMOT HOW TO V AT ZMOT HOW TO WIN AT ZMOT HOW TO WIN AT ZMOT HOW TO WIN AT ZMOT H HOW TO WIN AT ZMOT HOW TO WIN AT ZMOT HOW TO WIN AT ZMOT HOW TO V AT ZMOT HOW TO WIN AT ZMOT HOW TO WIN AT ZMOT HOW TO WIN AT ZMOT H HOW TO WIN AT ZMOT HOW TO WIN AT ZMOT HOW TO WIN AT ZMOT HOW TO V AT ZMOT HOW TO WIN AT ZMOT HOW TO WIN AT ZMOT HOW TO WIN AT ZMOT H HOW TO WIN AT ZMOT HOW TO WIN AT ZMOT HOW TO WIN AT ZMOT HOW TO V AT ZMOT HOW TO WIN AT ZMOT HOW TO WIN AT ZMOT HOW TO WIN AT ZMOT H HOW TO WIN AT ZMOT HOW TO WIN AT ZMOT HOW TO WIN AT ZMOT HOW TO V AT ZMOT HOW TO WIN AT ZMOT HOW TO WIN AT ZMOT HOW TO WIN AT ZMOT H HOW TO WIN AT ZMOT HOW TO WIN AT ZMOT HOW TO WIN AT ZMOT HOW TO V AT ZMOT HOW TO WIN AT ZMOT HOW TO WIN AT ZMOT HOW TO WIN AT ZMOT H HOW TO WIN AT ZMOT HOW TO WIN AT ZMOT HOW TO WIN AT ZMOT HOW TO V AT ZMOT HOW TO WIN AT ZMOT HOW TO WIN AT ZMOT HOW TO WIN AT ZMOT H HOW TO WIN AT ZMOT HOW TO WIN AT ZMOT HOW TO WIN AT ZMOT HOW TO $V$ AT ZMOT HOW TO WIN AT ZMOT HOW TO WIN AT ZMOT HOW TO WIN AT ZMOT H HOW TO WIN AT ZMOT HOW TO WIN AT ZMOT HOW TO WIN AT ZMOT HOW TO $V$ AT ZMOT HOW TO WIN AT ZMOT HOW TO WIN AT ZMOT HOW TO WIN AT ZMOT H HOW TO WIN AT ZMOT HOW TO WIN AT ZMOT HOW TO WIN AT ZMOT HOW TO V AT ZMOT HOW TO WIN AT ZMOT HOW TO WIN AT ZMOT HOW TO WIN AT ZMOT H HOW TO WIN AT ZMOT HOW TO WIN AT ZMOT HOW TO WIN AT ZMOT HOW TO V AT ZMOT HOW TO WIN AT ZMOT HOW TO WIN AT ZMOT HOW TO WIN AT ZMOT H HOW TO WIN AT ZMOT HOW TO WIN AT ZMOT HOW TO WIN AT ZMOT HOW TO V AT ZMOT HOW TO WIN AT ZMOT HOW TO WIN AT ZMOT HOW TO WIN AT ZMOT H HOW TO WIN AT ZMOT HOW TO WIN AT ZMOT HOW TO WIN AT ZMOT HOW TO V AT ZMOT HOW TO WIN AT ZMOT HOW TO WIN AT ZMOT HOW TO WIN AT ZMOT H HOW TO WIN AT ZMOT HOW TO WIN AT ZMOT HOW TO WIN AT ZMOT HOW TO V AT ZMOT HOW TO WIN AT ZMOT HOW TO WIN AT ZMOT HOW TO WIN AT ZMOT H HOW TO WIN AT ZMOT HOW TO WIN AT ZMOT HOW TO WIN AT ZMOT HOW TO V AT ZMOT HOW TO WIN AT ZMOT HOW TO WIN AT ZMOT HOW TO WIN AT ZMOT H HOW TO WIN AT ZMOT HOW TO WIN AT ZMOT HOW TO WIN AT ZMOT HOW TO V AT ZMOT HOW TO WIN AT ZMOT HOW TO WIN AT ZMOT HOW TO WIN AT ZMOT H HOW TO WIN AT ZMOT HOW TO WIN AT ZMOT HOW TO WIN AT ZMOT HOW TO $V$ AT ZMOT HOW TO WIN AT ZMOT HOW TO WIN AT ZMOT HOW TO WIN AT ZMOT H HOW TO WIN AT ZMOT HOW TO WIN AT ZMOT HOW TO WIN AT ZMOT HOW TO V 


\section{ГЛ А B A \\ 6}

\section{K A K 3 A B OEB A T b $Z M O T$}

«B 1940-е Betty Crocker nолучали 4000 - 5000 писем в день, и миь нанимали сотни сотрудников, чтобы писать персональные ответы. В 1960-е 350 тысяч человек вошли в Клуб Рецептов Бисквик. Это был пример 'социиальной среды' в то время, когда её ещзё не существовало.

С помощььо имеющцихся у нас новых цุифровых онлайн-инструментов, General Mills сегодня добились того же, ито и наши предщественники. Сейчас всё находится на кончиках наших пальцев.»

- МАрк АдДиКС

СТАРШИЙ ВИЦЕ-ПРЕЗИДЕНТ, ДИРЕКТОР ПО МАРКЕТИНГУ

General Mills

Я Аюблю эту цитату Марка АААикса, потому что она очень точно отражает, каким образом ZMOT стал совершенно новой частью старой траАиции.

Если Вы готовы начать побеждать в момент ZMOT, то начните со следующих четырёх вопросов:

- Когда вы начинаете вводить название своего продукта в строке поиска, но до того, как вы закончили, какие поисковые строки автоматически появляются ниже?
- Появляется ли ваш вебсайт или сообщение в верхней трети первой страницы результатов вашего поиска?

- Как выглядит ваш брэнд на основных рейтинговых и обзорных сайтах по вашей категории?

- Если кто-то ищет по ключевым фразам вашей ТВ рекламы, что они находят?

И вот ещё что. Попробуйте выполнить поиск вашего брэнда следующими тремя способами: 


\section{Рисунок 6-1: Упражнение по поиску}

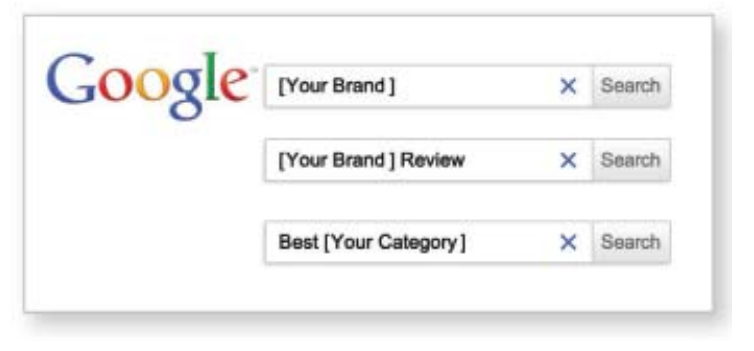

Ответы на эти вопросы, а также то, что вы увидите в результате, покажут, где вы находитесь в ZMOT.

По роду своих занятий мне приходится работать со многими компаниями и я обратил внимание, что те из них, которые преуспевают в ZMOT, используют несколько общих идей и стратегий. В этой главе я поговорю об этих идеях, а также опишу ряд инструментов, которые помогут вам спланировать свои собственные стратегии и измерить ваш успех. Надеюсь вы простите меня за то, что многие из них являются инструментами Google. B Google мы потратили много времени на размышления о ZMOT и естественно, это те решения, которые мне нравятся и известны лучше всего. (Большинство из них являются бесплатными.) Но конечно же, существует также большое количество других инструментов.

Итак, давайте поговорим о семи способах начать побеждать в ZMOT прямо сейчас:

1. Назначьте ответственного

2. Ищите свои Нулевые Моменты

3. Отвечайте на вопросы, которые вам задают

4. Оптимизируйте для ZMOT

5. Действуйте быстро

6. Не забывайте про видео

7. Подключайтесь!

\section{1. Назначьте ответственного}

Если я разговариваю с директором по маркетингу наедине, то мой первый вопрос бывает таким: «Кто у вас отвечает за ZMOT?»

Потому что если за это никто не отвечает, то работа не будет сделана. Если я спрошу вас, «Кто отвечает за ТВ?», или «Кто у вас отвечает за in-store маркетинг для FMOT?», или «Кто отвечает за то, что ваш зелёный горошек вовремя попадает на полки?», вы назовёте конкретное имя. Такое же конкретное имя вы должны назвать для ZMOT.

Этот человек должен быть наделён возможностью и готов работать с вашими агентствами - креативным, стратегическим, медийным и цифровым - а не прятаться в одиноком офисном кубике в конце зала. Когда вы планируете стратегию, он должен присутствовать на встрече. И у него должна быть возможность высказать своё мнение в отношении общего опыта для ваших потребителей. (Как вы увидите дальше, он должен уметь действовать быстро.)

Задайте себе вопрос: У меня есть бюджет для Нулевого Момента Истины? Или у меня есть только бюджет на вебсайт? Ваш новый ZMOT лидер не сможет ничего сделать с помощью сигаретного дыма и ключевых слов.

Чтобы ZMOT начал работать на вас, назначьте ответственного за него. 


\section{2. Ищите свои Нулевые Моменты}

Чем являются Нулевые Моменты Истины для вашего продукта, категории и брэнда? ZMOT для реактивных двигателей отличается от ZMOT для кукурузных хлопьев или служб онлайн знакомств. Вы и ваша команда должны в точности понимать, как люди ищут ваш продукт.

В начале этой главы я предложил вам ввести название своего продукта в строку поиска и посмотреть, какие связанные поисковые строки появляются по мере того, как вы набираете. (Все основные поисковые машины имеют такую функцию автозаполнения.) Поиски, которые вы увидите, будут наиболее популярными для названия вашего продукта. Если вы введёте «обувь для гольфа» и увидите, что наиболее популярные поиски - «Обувь для гольфа» и «обувь для гольфа купить», то вы сможете увидеть, где находятся Нулевые Моменты для вашего продукта.

На следующем шаге вы захотите использовать инструмент, который даст вам больше сведений об относящихся к вашей теме поисковых фразах и их популярности. Все поисковые машины имеют инструменты, которые могут показать поисковые запросы по заданной теме и то, насколько они популярны. Инструмент, который предлагает Google, называется Keyword Tool и является бесплатным. Введите «картофельные чипсы» и вы увидите десятки вариаций, начиная от «картофельные запеканки» (14800 поисков в месяц), «домашние чипсы» и «как приготовить чипсы». ${ }^{1}$ «Как приготовить чипсы» - производители чипсов, это ваш ZMOT!

Это только начало. Введите URL вашего вебсайта и инструмент проанализирует содержимое всех его страниц, посмотрит на поисковые запросы реальных пользователей, сделанные в течение 30 последних дней, и найдёт те из них, которые соответствуют вашему бизнесу. Затем инструмент выдаст вам список конкретных ключевых слов, которые использовали пользователи, и покажет вам вашу долю в результатах органического и платного поиска.

Настоящие ZMOT-ниндзя берут эти относящиеся к теме поиски и выполняют новые поиски, создавая разрастающиеся круги связанных терминов. Это будет вызовом для одного из самых умных членов вашей команды, так как требует решимости и искусства. Однако этот человек может стать супергероем ZMOT, если найдёт пользовательские данные, которые поставят ваш бизнес в правильное место, в правильное время, и с правильным сообщением.

Знайте свой Нулевой Момент и вы будете на пути к победе в ZMOT.

\section{3. Отвечайте на вопросы, которые вам задают}

Вот проблема, которую я наблюдаю довольно часто: я ищу что-то типа «какие ингридиенты входят в состав корма для собак?» И то, что я получаю в ответ, это реклама и ссылки от производителей корма для собак, которые говорят: «Получите скидку в $\$ 2$ на наш корм для собак!»

Так, а кто задавал вопрос про деньги? Не я. Я всё ещё ищу информацию.

Таким образом, это классический пример провала Нулевого Момента. Я ищу сведения о продукте, а получаю в ответ что-то типа взятки: «Кого волнует состав - получите скидку в два бакса!»

Не поймите меня неправильно: онлайн-купоны могут быть очень эффективны. Но не тогда, когда вопрос был совершенно о другом. Если вы продаёте корм для собак, то у вас должна быть целевая страница и рекламная кампания для вопросов по ингридиентам и калориям, а также для любого другого известного вам вопроса, который люди могут задать. Эта страница может сначала ответить на заданный вопрос, разрекламировать ваш продукт... и после этого вы сможете предложить скидку в два бакса. 
Как вы узнаете, какие вопросы люди задяют прямо сейчас? В Интернет вы найдёте большое количество инструментов, которые могут помочь. Вот два бесплатных от моей компании: Google Trends скажет вам, какие поиски популярны сейчас или на протяжении нескольких последних дней. Вы можете посмотреть диаграммы популярных запросов за последние 24 часа, 30 дней, и более. Введите название вашего бизнеса или любой другой поисковый термин и вы сможете посмотреть тенденции для него по всему миру.

Инструмент Insights for Search не даёт настолько свежую информацию как Trends, но он показывает больше сведений о поисках, которые относятся к конкретно вашему бизнесу. Введите название продукта и вы сможете увидеть подъём связанных с ним поисков, штаты и города, где эти поиски популярны, и многое другое. Если вы делаете чугунные украшения, а популярным поиском в течение последнего месяца был «новые титановые украшения», то вы обнаружите это здесь.

Аналитические инструменты, такие как WebTrends и Adobe Omniture (и Google Analytics!) идут со стандартными встроенными механизмами, которые покажут, на правильные ли вопросы вы отвечаете на своём сайте. Например, посмотрите на такую метрику, как показатель отказов (Bounce Rate). Она измеряет процент людей, которые видят только одну страницу вашего сайта - люди которые приходят, смотрят и уходят.

Найдите страницы на вашем сайте с высоким показателем отказов. Обычно вам нужно поддерживать показатель отказов на уровне менее $30 \%$. Это означает, что только трое из десяти приведённых на сайт посетителей покинут его сразу же. Более высокий показатель означает, что существует большой разрыв между тем, что люди ожидают увидеть, приходя на вашу страницу, и тем, что они реально видят, придя туда. Понизьте этот показатель и вы будете знать, что отвечаете на вопросы своих потребителей.

Помните и о том, что люди задают много разных вопросов. Средний покупатель использует для принятия решения более десяти источников информации. ${ }^{2}$ Помните о мотивациях, о которых мы говорили ранее - экономия времени, экономия денег и поиск лучшего продукта. Вопросы, на которые вам нужно ответить, часто будут лежать в одной плоскости с этими мотивациями.

B ZMOT недостаточно просто знать вопросы, которые задают люди, необходимо отвечать на них.

\section{4. Оптимизируйте дАя ZMOT}

Итак: вы знаете все ZMOT своего брэнда, вы знаете, какие вопросы задают люди, и вы знаете, где вы появляетесь.

Конечно же, следующий вопрос - как увеличить свою видимость?

Время начинать думать креативно. Я разговаривал с Дэвидом Алмаси, Директором по Интернет в администрации Белого Дома при президенте Джордже Буше, и он рассказал мне потрясающую историю:

Это одна из лучших историй про оптимизацию для поисковых машин, которую я когда-либо слышал. В самой середине дебатов по здравоохранению администрация Обамы начала отслеживать, какие вопросы люди задают через Интернет о законопроекте по здравоохранению. И они обнаружили, что наиболее часто задаваемый вопрос был просто-напросто, 'Что содержится в законопроекте по здравоохранению?' Таким образом, они набросали черновик сообщения в блоге сайта Белого Дома и озаглавили его в точности, 'Что содержится в законопроекте по здравоохранению?' 
Это сработало! Во время дебатов, если бы вы набрали эту фразу, то на первом месте в результатах поиска появилась бы именно әта запись в блоге на WhiteHouse.gov, которая была спеццильно посвящена планам Президента по здравоохранению.

Мне нравится в этой истории то, что у вас есть команда, которая понимает, как работает веб, как люди используют веб для поиска информацции, и они использовали свой собственный сайт для своей выгодь. И самое иенное заключается в том, что это ничего не стоит. Это ничего не стоило, за исключением времени, которое было потрачено на написание того сообщения в блоге.

Кстати, когда я проверял в последний раз, сообщение Белого Дома по-прежнему было номером один для этой поисковой фразы.

Стимул для потребителей больше не должен исходить от вас, и в ZMOT по большей части так скорее всего и будет. Хорошая возможность стимула может происходить от газетной статьи, общественной проблемы, или даже рекламы конкурента.

«Дни, когда вы контролировали сообщение, безвозвратно закончились. В лучшем случае вы будете приглашены и должны будете принимать участие и создавать вместе с потребителями.» Так говорит Венди Кларк. Она немножко в курсе темы: она является старшим вицепрезидентом по интегрированным маркетинговым коммуникациям и возможностям в компании Coca-Cola.

Как отмечает Венди, вы должны поправить содержимое для всех трёх традиционных частей разговора: оплаченной, в собственном владении, заслуженной. Она добавляет четвёртую часть: совместную.

Опдаченная - это реклама и информационные материалы, которые вы оплачиваете самостоятельно.

В собственном вдадении - это средства, которые контролирует ваша компания и которые можно использовать для продвижения и укрепления вашего брэнда. B случаe Coca-Cola, это их упаковка (около 1.7 миллиарда порций ежедневно) и парк грузовых машин доставки, которые можно использовать в качестве коммуникационных носителей.

Заслуженная - это рейтинги, отзывы и социальные среды, о которых мы говорили ранее: Испытывают ли люди желание говорить о вашем продукте? Если да, то что они говорят? Coca-Cola имеет сотни тысяч последователей в Твиттере и миллионы фэнов в Фэйсбук, и эти пользователи в целом образуют персональную сеть ещё большего размера.

Совместная - это области, которые вы не можете контролировать напрямую, но где может фигурировать и продвигаться ваш брэнд, как например в точке продаж, или, в случае Coca-Cola, в ресторанах McDonald's.

Это то, где ZMOT может помочь вам добиться воздействия, даже если вы (ещё) не производите 1.7 миллиарда порций ежедневно. Вы уделяете внимание тому, как потребители передают ваше сообщение между собой? Вы сами создаёте привлекательное и легко распространяемое содержимое? Если вы представляете местный бизнес, работаете ли вы с продуктами FourSquare или Google Places, которые помогут вашим потребителям поделиться заработанной любовью? 
А думаете ли вы о мобильных устройствах? Это больше не «гости из будущего» - это настоящее.

B 2010 году Google провели опрос и обнаружили (к нашему большому удивлению), что только $21 \%$ наших топовых рекламодателей имеют вебсайты, оптимизированные под мобильные устройства. ${ }^{3}$ Остальные 79\% их не имеют. В моём понимании, цифры должны быть обратными.

То, что ваш сайт можно посмотреть на смартфоне, вовсе не означает, что по нему легко перемещаться и использовать его. Попробуйте прямо сейчас открыть свой собственный сайт со своего мобильного устройства. Часто ли приходится изменять масштаб изображения? Легко ли вы можете найти вещи? Каковы основные действия, которые мобильные покупатели и исследователи захотят выполнить на вашем сайте? Получить цены? Посмотреть информацию о продукте? Эти вещи должны быть легко доступны в формате, который подходит для небольших экранов и больших пальцев.

Вот некоторые советы специально для мобильных устройств, частично основанные на сборе данных, который мы выполнили в прошлом году:

- Запускайте и отслеживайте мобильные кампании отдельно от остальных. Не мутите воду. Исключительно мобильные кампании на 11.5\% более эффективны по сравнению с гибридными десктоп-мобильными кампаниями. ${ }^{4}$

- В мобильных кампаниях первая позиция значит ещё больше. Это верно и в случае результатов поиска, и в случае рекламных позиций. Цифровая полка становится очень маленькой на экране мобильного устройства! Смещение с первой позиции на четвёртую на мобильном телефоне может означать падение CTR более чем на $90 \%{ }^{5}$

- Используйте таргетирование по устройствам. Знаете ли вы, что мы создали несколько различных версий книги, которую вы сейчас читаете? Каждая из них создана под конкретное устройство. В онлайн-мире несложно определить, какое устройство использует пользователь, и предложить нужный формат для максимального эффекта чтения ZMOT, а также отслеживать использование различных устройств для определения того, какое из них наиболее популярно и работает лучше всего.

«Ещё раз, ещё раз, и ещё раз», говорит Лиза Гевелбер, директор по маркетингу Google, Северная и Южная Америка. «Данные побеждают мнения, и это основное правило для мобильной, десктоп или любой другой ZMOT кампании. Пробуйте что-то новое, тщательно отслеживайте результат, затем запускайте то, что работает, и отключайте то, что нет. В этом и заключается прелесть онлайн: вы можете менять и исправлять вещи на лету.»

Оптимизация вашего содержимого для ZMOT является непрерывным процессом, а не единоразовым действием. Награда вполне этого стоит.

\section{5. Действуйте быстро}

В мире ZMOT скорость побеждает совершенство.

Вы не можете использовать классический образ мышления большого ежегодного маркетингового плана с развёртываниями, планируемыми за 12 месяцев до их начала. Вы должны быть быстрее и гибче.

Вот пример, который я использую постоянно: через день после того, как Lady Gaga выпустила видеоклип к своей песне "Telephone", мы неожиданно начали видеть поиски терминов типа «Beyonce жёлтые тени» и «Веyonce жёлтая косметика». 
Потому что на протяжении двух третей этого девятиминутного видео Beyonce появлялась на сцене в жёлтом платье, жёлтой ковбойской шляпе и с... жёлтыми тенями на глазах.

Теперь, если вы продаёте тени для глаз, хотели бы вы оказаться там, когда случились все эти поиски? Я думаю что хотели бы. Ещё до того, как покупатель подойдёт в магазине к проходу с косметикой, она скажет, «Я хочу так выглядеть. Помогите мне добиться этого!» Но вы должны быть готовы действовать быстро и появляться с содержимым, которое такие потребители могут найти немедленно.

Вот прекрасный пример скорости действия ZMOT: Заправка Miracle Whip ${ }^{\circledR}$. Стефен Колберт подготовил отчёт, высмеивающий распространение сэндвичей, в своём шоу The Colbert Report осенью 2009 года. Команда Miracle Whip ответила с поразительной смелостью, трансформировав критику Колберта в смешную войну майонез-против-Miracle Whip. Неожиданно люди, которые искали имя Колберта (или Miracle Whip) стали обнаруживать онлайн-рекламу, которая говорила: «Колберт не может справиться с великолепным вкусом Miracle Whip! На чьей стороне вы?»

Эти смешные ZMOT-рекламки отправляли посетителей на веб-страницы и видео, созданные компанией, укрепляющие сообщение Miracle Whip: «Мы не будем понижать голос!» Затем команда Miracle Whip опубликовала открытое письмо Колберту в газетах по всей стране, а также быстро поменяла три рекламных модуля на ТВ, направленные на ведущего во время его собственного шоу.

«Война» стала вирусной. Даже сейчас поиски типа "Stephen Colbert Miracle Whip" возвращают десятки отличных историй и публикаций в блогах о споре. Победитель в ZMOT: Miracle Whip.

Действуйте быстро и вы сможете хорошо закрепиться в ZMOT.

\section{6. Не забывайте про видео}

Знаете, какое поисковое окно находится на втором месте в мире по популярности? Это строка поиска YouTube. ${ }^{6}$

Большая часть ZMOT теперь является визуальной. В конце концов, мобильные телефоны могут показывать и снимать видео. Вы должны быть готовы к этому и держать наготове видео для ваших потребителей.

Когда я разговариваю с большими индустриальными компаниями, я часто предлагаю им ввести меня в замешательство, перебирая необычные темы для видео поиска - например, «полупроводниковые диоды» или «смешивание цемента». И какой бы ни была тема, в десяти случаях из десяти мы находим пачку видео о ней. Вы будете удивлены, как много тысяч людей смотрят видео о полупроводниках или цементе, обезболивающих или правильных занятиях тяжёлой атлетикой.

Потребители брэндов обычно ищут два типа видео:

- Обзоры и демонстрации продуктов

- Самоучители и советы экспертов

Для брэндов в сегменте В2В также нужно отметить:

- Тематические исследования

- Интеллектуальное лидерство 
Эти видео могут быть как высокобюджетными, так и простыми роликами с участием всего одного из членов вашей команды (или вас самих!) и камеры. Возможно вы слышали о Гэри Вайнерчук, который превратил винный магазин под названием The Wine Library в Нью Джерси в сенсацию, просто записывая каждый день одно короткое видео про вино в своём магазине. О нём написали The Wall Street Journal и The New York Times, он был у Конана О'Брайена, Эллен Дегенерес и Джима Крамера, и всё только благодаря своим видео. На самом деле, если вы сегодня наберёте в Google "wine videos", он будет первым в списке результатов. С помощью видео он побеждает в ZMOT. Ваша команда может делать то же самое.

Видео имеет также одно большое преимущество: фактор «посмотри это!» Видео удивительно легко отправить по почте, разместить в социальной сети, или внедрить в блог или на страницу сайта. Это прекрасный способ привлечь внимание к вашему продукту. Помня об этом, важно сделать так, чтобы ваше видео можно было легко передавать от одного потребителя к другому.

Когда мы говорим о видеорекламе в ZMOT, то вы можете быстро заработать хорошие очки, просто разместив онлайн свою телевизионную рекламу. Когда мы анализировали 32 различные кампании, которые проводились с помощью YouTube в 2009 и 2010 годах в Германии, то обнаружили, что YouTube добавил 3.4 процентных пункта дополнительного охвата к ТВ охвату. Мы узнали, что 64\% пользователей, которые увидели рекламу на YouTube, не видели кампанию по ТВ. Это новые пользователи! Пересечение между пользователями, которым показывали одну и ту же рекламу на ТВ и YouTube, составило всего 1.9\%.7

Но вы также должны подумать о роликах, которые созданы для просмотра онлайн. Онлайн-пользователи обладают другим образом мышления - они хотят закуски! Длительность видео от 15 до 30 секунд обычно является подходящей. Люди не всегда заинтересованы просматривать онлайн то, что они только что посмотрели на экране телевизора. Они будут искать большего: съёмки за пределами сцены, комментарии или вещи, которые обычно вырезают при монтаже. Я знаю, что у вас есть все эти замечательные штуки, так почему бы не использовать их?

Я говорил, что ZMOT должен получать в маркетинговом плане внимание наравне с остальными. Внутри ZMOT видео также должно получать внимание наравне с остальным.

\section{7. Подкдючайтесь!}

\section{«Появление на публике составляет} $80 \%$ от всей жизни.»

$$
\text { Вуди Аллен }{ }^{8}
$$

Кто бы мог подумать, что Вуди Аллену будет что сказать про ZMOT?

Прелесть онлайн мира такова: вы можете подключиться прямо сейчас. И прелесть ZMOT состоит в том, что лучшим способом преуспеть в нём является подключение прямо сейчас. Вам не нужен комитет и пятилетний план. Вам просто нужно знание того, что это может обеспечить хороший выигрыш для вашего бизнеса, храбрость, и желание повеселиться и попробовать новые вещи.

Бизнес, который преуспевает в ZMOT, это такой бизнес, который проходит через циклы, как говорит Лиза Гевелбер: тестируйте, учитесь, оптимизируйте и затем пробуйте снова. «Терпите неудачу быстрее.» - так любит говорить мой коллега Авинаш Каушик. Ускорьте весь цикл. Чем быстрее вы потерпите неудачу, тем быстрее вы узнаете, что работает. Расценивайте свои маркетинговые онлайн-кампании, как если бы они всегда были в бета-версии. 
Когда вы назначаете кого-то быть ответственным за ZMOT, как я предлагал ранее, убедитесь, что этот человек относится к типу самозаводящихся людей, который любит атаковать проблемы. И убедитесь, что вы дали ему власть и свободу начинать действовать прямо сейчас.

\section{Ещё одна мысдь}

Вышеперечисленное составляет семь шагов, некоторые из которых являются простыми, а некоторые - чуть более сложными. Выполняйте их все и вы будете на пути к успеху в ZMOT.

А теперь я хочу дать задание вам: в течение следующих нескольких дней обращайте внимание на свои собственные решения о покупке и исследования. Как вы делаете выбор? Бьюсь об заклад, вы будете удивлены тем, как часто вы будете обнаруживать себя в ZMOT. Будучи там, подумайте о том, как ваши собственные потребители будут искать вас похожим образом.

А теперь подключайтесь! 
NEXT? MOTS NEXT? MOTS NEXT? MOTS NEXT? MOTS NEXT? MOTS NEXT? MC IEXT? MOTS NEXT? MOTS NEXT? MOTS NEXT? MOTS NEXT? MOTS NEXT? MC MOTS NEXT? MOTS NEXT? MOTS NEXT? MOTS NEXT? MOTS NEXT? NEXT? MOTS NEXT? MOTS NEXT? MOTS NEXT? MOTS NEXT? MOTS NEXT? MC IEXT? MOTS NEXT? MOTS NEXT? MOTS NEXT? MOTS NEXT? MOTS NEXT? MC NEXT? MOTS NEXT? MOTS NEXT? MOTS NEXT? MOTS NEXT? MOTS NEXT? NEXT? MOTS NEXT? MOTS NEXT? MOTS NEXT? MOTS NEXT? MOTS NEXT? MC IEXT? MOTS NEXT? MOTS NEXT? MOTS NEXT? MOTS NEXT? MOTS NEXT? MC NEXT? MOTS NEXT? MOTS NEXT? MOTS NEXT? MOTS NEXT? MOTS NEXT? NEXT? MOTS NEXT? MOTS NEXT? MOTS NEXT? MOTS NEXT? MOTS NEXT? MC IEXT? MOTS NEXT? MOTS NEXT? MOTS NEXT? MOTS NEXT? MOTS NEXT? MC MOTS NEXT? MOTS NEXT? MOTS NEXT? MOTS NEXT? MOTS NEXT? NEXT? MOTS NEXT? MOTS NEXT? MOTS NEXT? MOTS NEXT? MOTS NEXT? MO IEXT? MOTS NEXT? MOTS NEXT? MOTS NEXT? MOTS NEXT? MOTS NEXT? MC NEXT? MOTS NEXT? MOTS NEXT? MOTS NEXT? MOTS NEXT? MOTS NEXT? NEXT? MOTS NEXT? MOTS NEXT? MOTS NEXT? MOTS NEXT? MOTS NEXT? MC IEXT? MOTS NEXT? MOTS NEXT? MOTS NEXT? MOTS NEXT? MOTS NEXT? MC NEXT? MOTS NEXT? MOTS NEXT? MOTS NEXT? MOTS NEXT? MOTS NEXT? NEXT? MOTS NEXT? MOTS NEXT? MOTS NEXT? MOTS NEXT? MOTS NEXT? MC IEXT? MOTS NEXT? MOTS NEXT? MOTS NEXT? MOTS NEXT? MOTS NEXT? MC NEXT? MOTS NEXT? MOTS NEXT? MOTS NEXT? MOTS NEXT? MOTS NEXT? NEXT? MOTS NEXT? MOTS NEXT? MOTS NEXT? MOTS NEXT? MOTS NEXT? MC IEXT? MOTS NEXT? MOTS NEXT? MOTS NEXT? MOTS NEXT? MOTS NEXT? MC MOTS NEXT? MOTS NEXT? MOTS NEXT? MOTS NEXT? MOTS NEXT? NEXT? MOTS NEXT? MOTS NEXT? MOTS NEXT? MOTS NEXT? MOTS NEXT? MC IEXT? MOTS NEXT? MOTS NEXT? MOTS NEXT? MOTS NEXT? MOTS NEXT? MC NEXT? MOTS NEXT? MOTS NEXT? MOTS NEXT? MOTS NEXT? MOTS NEXT? NEXT? MOTS NEXT? MOTS NEXT? MOTS NEXT? MOTS NEXT? MOTS NEXT? MC IEXT? MOTS NEXT? MOTS NEXT? MOTS NEXT? MOTS NEXT? MOTS NEXT? MC NEXT? MOTS NEXT? MOTS NEXT? MOTS NEXT? MOTS NEXT? MOTS NEXT? NEXT? MOTS NEXT? MOTS NEXT? MOTS NEXT? MOTS NEXT? MOTS NEXT? MC IEXT? MOTS NEXT? MOTS NEXT? MOTS NEXT? MOTS NEXT? MOTS NEXT? MC NEXT? MOTS NEXT? MOTS NEXT? MOTS NEXT? MOTS NEXT? MOTS NEXT? NEXT? MOTS NEXT? MOTS NEXT? MOTS NEXT? MOTS NEXT? MOTS NEXT? MC IEXT? MOTS NEXT? MOTS NEXT? MOTS NEXT? MOTS NEXT? MOTS NEXT? MC NEXT? MOTS NEXT? MOTS NEXT? MOTS NEXT? MOTS NEXT? MOTS NEXT? NEXT? MOTS NEXT? MOTS NEXT? MOTS NEXT? MOTS NEXT? MOTS NEXT? MC IEXT? MOTS NEXT? MOTS NEXT? MOTS NEXT? MOTS NEXT? MOTS NEXT? MC MOTS NEXT? MOTS NEXT? MOTS NEXT? MOTS NEXT? MOTS NEXT? NEXT? MOTS NEXT? MOTS NEXT? MOTS NEXT? MOTS NEXT? MOTS NEXT? MC IEXT? MOTS NEXT? MOTS NEXT? MOTS NEXT? MOTS NEXT? MOTS NEXT? MC 


\section{ГЛ А В А}

\section{7}

\section{Ч ТОДАЛЬШЕ?}

«Mы скоро увидим слияние всех моментов истины. Вы будете смотреть на продукт на полке и использовать свой телефон для поиска информации и чтения отзывов о нём, а потом вы может быть решите, что продукт действительно хорош, и поставите ему 'like' для своих друзей, и всё это в течение минуты.

Путешествие покупателя, которое раньше занимало дни, недели, или месяизы, произошло за секунды.»

\section{- МэтТ Муг \\ ОСНОВАТЕЛЬ И СЕО \\ ViewPoints NeTWORK}

\section{Какое восхитительное время} А^я маркетолога.

Мир меняется с невероятно высокой скоростью. Лоррэйн Тухилл, глобальный Директор по Маркетингу Google, делится цифрами, которые говорят сами за себя:

Десять лет назад менее $2 \%$ населения было онлайн. Сейчас это число составляет более $25 \%$ по всему миру, и близко к $100 \%$ во многих странах. Две трети всего населения земного шара имеют мобильные телефоны. К 2020 году 5 миллиардов человек будут иметь доступ в Интернет и 10 миллиардов будут обладать мобильными телефонами.

В этом трансформационном будущем потребители имеют доступ к ZMOT везде и в реальном времени. Потребители ищут и находят рейтинги, отзывы, рекламу, видео, и информацию, передаваемую из уст в уста, и прямо там же добавляют свои собственные мысли и мнения - где бы это не происходило.

И честно говоря, мы уже прошли большую часть пути к этому будущему.

\section{Мобильные устройства явдяются катализатором}

Не позволяйте никому говорить вам, что мобильные устройства - «это будущее». Они уже здесь. Лоррэйн Тухилл предоставила отличную статистику: две трети из нас спят, имея свой телефон под рукой. ${ }^{1}$ Это почти 3.3 миллиарда человек, которые имеют при себе телефон днём и ночью.

Пути, которыми мы пользуемся мобильными телефонами, продолжат меняться. По мере распространения технологии GPS, для местного бизнеса в чарты попадут сервисы, основанные на определении местоположения. И кто знает, что станет следующим хитом? Мэтт Муг из ViewPoints Network считает, что это будут телефоны, которые читают бар-коды и включают ZMOT моменты для всё большего и большего числа покупателей: 
Когда покупатели имеют в своём кармане сканер бар-кодов, они с помощью одного клика могут найти всё, что они хотят знать: кому из их друзей нравятся эти товары, что входит в состав, как их можно использовать разными способами, наука, содержимое и сведения, которые скрываются за этим продуктом. Вын не можете недооценивать то, как люди собираются использовать эту возможность.

По мере того, как потребители будут открывать информацию, они будут добавлять свои собственные данные и мнения в разговор на своих собственных сайтах и в блогах, в социальных сетях и новыми способами, о которых никто пока ещё не думал. Проще говоря, мобильные телефоны являются МОТ устройствами.

\section{Схождение всех МОТ}

Ранее я говорил, что воронка продажи превращается во что-то менее линейное - скорее похожее на нейрон, с расходящимися во все стороны импульсами. Эти импульсы распространяются всё быстрее и быстрее. Для потребителей, Нулевой (ZMOT), Первый (FMOT) и Второй (SMOT) Моменты Истины сближаются поминутно.

Наиболее очевидный пример - это момент рядом с магазинной полкой: когда вы исследуете, принимаете решение, покупаете и делитесь тем, что вы узнали, всё одновременно. Но то же самое происходит теперь каждый день, во всех сферах жизни.

Скажем, я отправляюсь в отпуск и мне нужно найти гостиницу. Я отправляюсь в Интернет, чтобы оценить возможности.(ZMOT!) Я читаю отзывы тех людей, кто уже останавливался в этой гостинице (их SMOT, мой ZMOT) и смотрю на карте расположение гостиницы. В концеконцов я сужаю поиск до двух гостиниц и иду на их вебсайты, чтобы посмотреть фотографии и расценки (FMOT) перед тем, как я зарезервирую номер онлайн.

Мы с семьёй отправляемся в поездку, замечательно проводим время (SMOT), а в последний день мы прибываем в аэропорт на час раньше. Я беру свой мобильный телефон и размещаю свой собственный отзыв о гостинице на TripAdvisor. И ещё до того, как я сяду на самолёт до дома, мой SMOT станет чьим-то ещё ZMOT. Один MOT приводит к другому.

\section{Распространение видео}

Нынешние молодые люди носят телефоны со встроенной камерой в кармане с тех самых пор, как у них эти карманы появились. Им чрезвычайно комфортно использовать видео, чтобы рассказать друг другу о продуктах в своей жизни. Если рынки являются разговорами, как сказал Док Серлс в The Cluetrain Manifesto, эти разговоры больше похожи на фильмы.

Вообще говоря, ZMOT становится визуальным на всех фронтах, как отмечает Марк Аддикс из General Mills:

Мьи можем прийти в место, где вы показываете покупателю конечньй результат, а они могут деконструировать его прямо там.

Скажем, приближается день рождения моей шестилетней дочери и у меня не очень много времени. Я знаю, что моя дочь сходит с ума от Диснеевских принцесс, так может я быстро поищу онлайн 'вечеринка на день рождения с принцессой'. И то, что я должен обнаружить, это видео продолжительностью около 2 минут, посмотрев которое, я скажу -да, я могу это сделать. Это выглядит здорово! 


\begin{abstract}
И после этого мй можем предложить этолу покупателю дополнительные услуги. Нужны декорации? Как выглядят приглашения? Что мия делаем во время вечеринки? Всё это происходит до того, как появляются традиционные носители - это происходит по расписанию покупателя, в его время.
\end{abstract}

Если вы маркетолог, я надеюсь, что вы поощряете своих потребителей делать видео о вашем продукте, которое другие смогут найти в Нулевой Момент Истины. Никогда не забывайте, что ваши потребители находятся впереди вас, и они готовы внести свой вклад в ZMOT в реальном времени.

\title{
За пределы полки
}

К 2020 году мы будем соединяться на скоростях в один гигабайт в секунду. Это в 500 раз быстрее текущих скоростей подключения в США, и почти в 2000 раз быстрее, чем Wi-Fi в гостинице, где я останавливался вчера. Звучит слишком отдалённо? Южная Корея достигнет этих скоростей в 2012 году. ${ }^{2}$

Такая скорость изменит нашу жизнь и маркетинг везде: в бизнесе, в политике, в образовании, называйте что угодно. Как за этим смогут поспевать маркетологи?

«Скажите да.» Это одна из любимых фраз Лоррэйн Тухилл, и я обожаю её. Всегда легко проявить предосторожность и сказать «нет». Но сейчас идеи поступают отовсюду. Воспользуйтесь этим! Говорите «да» как можно чаще. Будьте подвижными. Принимайте риски, пытайтесь делать новые вещи, учитесь и удивляйтесь.

Какая из больших компаний первой назначит Директора по ZMOT? В какой бизнес-школе откроется первый курс по ZMOT? Кто откроет первое агентство Нулевого Момента? Будущее принадлежит маркетологам, которые осознают мощь ZMOT, набирают людей под это, и даже проводят для этого реорганизацию.

Ким Кадлек из Johnson \& Johnson говорит следующим образом: «Традиционная рекламная модель прерывает содержимое, но вопрос стоит так: 'Как стать частью содержимого?' Как соединиться с чьим-то опытом так, чтобы это было выгодно, а не отталкивало от этого опыта? Это и вызов и возможность одновременно.»

\section{Сдедующее покодение}

Однажды вечером, во время работы над этой книгой, я прошёл через спальню, где моя дочь играла на Nintendo в новую игру, которую она называла Мазнянавты (Scribblenauts). Позже я вернулся в комнату, а она всё ещё продолжала играть.

Я наблюдал за ней некоторое время, а потом спросил: «Где ты услышала про эту игру?» Она ответила, «Я увидела рекламный ролик и он мне понравился, поэтому я посмотрела описание на своём телефоне. Я узнала, что это игра-головоломка и у неё хороший рейтинг, поэтому я использовала часть своих денег на подарочной карте, чтобы купить её в магазине.»

Я совершенно уверен, что она сказала так не для того, чтобы попасть в эту книгу. Для следующих поколений ZMOT на самом деле настолько прост.

По правде говоря, он настолько же прост для всех нас.

Всё, что вам нужно сделать сейчас, это подключить ваш бизнес к разговору. Идите на риск. Говорите да. Задайте своей команде вопрос, который мы в Google задаём клиентам каждый день: «Вы готовы завоевать Нулевой Момент Истины?» 



\section{АВИГАЙТЕСЬ B П ЕРЕ}

Готовы к большему?

Присоединяйтесь ко мне на сайте ZeroMomentOfTruth.com. Я буду отслеживать последние новости и новые идеи от репортёров, торговцев, блоггеров и (разумеется) маркетологов всех мастей. Это единое место для новостей Нулевого Момента, свежих взглядов и видеоинтервью с соавторами каждой части этой книги. И в соответствии с духом ZMOT, присоединяйтесь к разговору прямо на сайте. Мне будет интересно услышать вас.

Сейчас на самом деле восхитительное время для того, чтобы быть маркетологом. Увидимся в ZMOT! 
ENDIX APPENDIX APPENDIX APPENDIX APPENDIX APPENDIX APPENDIX APPENDIX API PENDIX APPENDIX APPENDIX APPENDIX APPENDIX APPENDIX APPENDIX APPENDIX AP NDIX APPENDIX APPENDIX APPENDIX APPENDIX APPENDIX APPENDIX APPENDIX API ENDIX APPENDIX APPENDIX APPENDIX APPENDIX APPENDIX APPENDIX APPENDIX API PENDIX APPENDIX APPENDIX APPENDIX APPENDIX APPENDIX APPENDIX APPENDIX AP NDIX APPENDIX APPENDIX APPENDIX APPENDIX APPENDIX APPENDIX APPENDIX API ENDIX APPENDIX APPENDIX APPENDIX APPENDIX APPENDIX APPENDIX APPENDIX API PENDIX APPENDIX APPENDIX APPENDIX APPENDIX APPENDIX APPENDIX APPENDIX AP NDIX APPENDIX APPENDIX APPENDIX APPENDIX APPENDIX APPENDIX APPENDIX API ENDIX APPENDIX APPENDIX APPENDIX APPENDIX APPENDIX APPENDIX APPENDIX API PENDIX APPENDIX APPENDIX APPENDIX APPENDIX APPENDIX APPENDIX APPENDIX AP NDIX APPENDIX APPENDIX APPENDIX APPENDIX APPENDIX APPENDIX APPENDIX API ENDIX APPENDIX APPENDIX APPENDIX APPENDIX APPENDIX APPENDIX APPENDIX API PENDIX APPENDIX APPENDIX APPENDIX APPENDIX APPENDIX APPENDIX APPENDIX AP :NDIX APPENDIX APPENDIX APPENDIX APPENDIX APPENDIX APPENDIX APPENDIX API ENDIX APPENDIX APPENDIX APPENDIX APPENDIX APPENDIX APPENDIX APPENDIX API PENDIX APPENDIX APPENDIX APPENDIX APPENDIX APPENDIX APPENDIX APPENDIX AP NDIX APPENDIX APPENDIX APPENDIX APPENDIX APPENDIX APPENDIX APPENDIX API ENDIX APPENDIX APPENDIX APPENDIX APPENDIX APPENDIX APPENDIX APPENDIX API PENDIX APPENDIX APPENDIX APPENDIX APPENDIX APPENDIX APPENDIX APPENDIX AP NDIX APPENDIX APPENDIX APPENDIX APPENDIX APPENDIX APPENDIX APPENDIX API ENDIX APPENDIX APPENDIX APPENDIX APPENDIX APPENDIX APPENDIX APPENDIX API PENDIX APPENDIX APPENDIX APPENDIX APPENDIX APPENDIX APPENDIX APPENDIX AP NDIX APPENDIX APPENDIX APPENDIX APPENDIX APPENDIX APPENDIX APPENDIX API ENDIX APPENDIX APPENDIX APPENDIX APPENDIX APPENDIX APPENDIX APPENDIX API PENDIX APPENDIX APPENDIX APPENDIX APPENDIX APPENDIX APPENDIX APPENDIX AP NDIX APPENDIX APPENDIX APPENDIX APPENDIX APPENDIX APPENDIX APPENDIX API ENDIX APPENDIX APPENDIX APPENDIX APPENDIX APPENDIX APPENDIX APPENDIX API PENDIX APPENDIX APPENDIX APPENDIX APPENDIX APPENDIX APPENDIX APPENDIX AP NDIX APPENDIX APPENDIX APPENDIX APPENDIX APPENDIX APPENDIX APPENDIX API ENDIX APPENDIX APPENDIX APPENDIX APPENDIX APPENDIX APPENDIX APPENDIX API PENDIX APPENDIX APPENDIX APPENDIX APPENDIX APPENDIX APPENDIX APPENDIX AP NDIX APPENDIX APPENDIX APPENDIX APPENDIX APPENDIX APPENDIX APPENDIX API ENDIX APPENDIX APPENDIX APPENDIX APPENDIX APPENDIX APPENDIX APPENDIX API PENDIX APPENDIX APPENDIX APPENDIX APPENDIX APPENDIX APPENDIX APPENDIX AP NDIX APPENDIX APPENDIX APPENDIX APPENDIX APPENDIX APPENDIX APPENDIX API ENDIX APPENDIX APPENDIX APPENDIX APPENDIX APPENDIX APPENDIX APPENDIX API PENDIX APPENDIX APPENDIX APPENDIX APPENDIX APPENDIX APPENDIX APPENDIX AP NDIX APPENDIX APPENDIX APPENDIX APPENDIX APPENDIX APPENDIX APPENDIX API ENDIX APPENDIX APPENDIX APPENDIX APPENDIX APPENDIX APPENDIX APPENDIX API PENDIX APPENDIX APPENDIX APPENDIX APPENDIX APPENDIX APPENDIX APPENDIX AP NDIX APPENDIX APPENDIX APPENDIX APPENDIX APPENDIX APPENDIX APPENDIX API ENDIX APPENDIX APPENDIX APPENDIX APPENDIX APPENDIX APPENDIX APPENDIX API PENDIX APPENDIX APPENDIX APPENDIX APPENDIX APPENDIX APPENDIX APPENDIX AP NDIX APPENDIX APPENDIX APPENDIX APPENDIX APPENDIX APPENDIX APPENDIX API ENDIX APPENDIX APPENDIX APPENDIX APPENDIX APPENDIX APPENDIX APPENDIX API 


\section{ПР ИЛО ЖЕ Н И Е}

Для любителей данных ZMOT: Это приложение целиком содержит дополнительные данные по совместному исследованию Нулевого Момента Истины Google/Shopper Sciences, проведённого в США и опубликованного в апреле 2011 года.

\section{Цели исследования:}

Определить на макро и индустриальном уровне как покупатели и потребители принимают решения, основываясь на понимании трёх ключевых компонентов: 1) средняя продолжительность цикла принятия решения о покупке, 2) источники, которые были использованы для принятия окончательных решений, и 3) влияние, которое каждый источник имел на принятие окончательных решений.

\section{Метододогия:}

Shopper Sciences использовали онлайн-опрос для сбора данных от 5000 покупателей. Технология проведения опроса включала в себя новейшие инструменты программирования на основе Flash для создания интерактивной и привлекательной среды для респондентов. Количественный анализ поведения при принятии решений был проведён по покупкам, услугам и голосованиям. Данные собирались по следующим категориям: автомобили, здравоохранение, продукты питания, красота/личная гигиена, потребительская техника, путешествия, рестораны, кредитные карты, страхование, инвестиции, банки и выбор кандидатов на публичных выборах. Размеры выборки по категориям указаны в Таблице А-10.

\section{Дополнительные резудьтаты:}

Покупатели не замещают традиционные источники новыми источниками. Вместо этого они значительно увеличивают свою активность, чтобы переработать новую информацию.

Рисунок А-1: Количество источников и использование
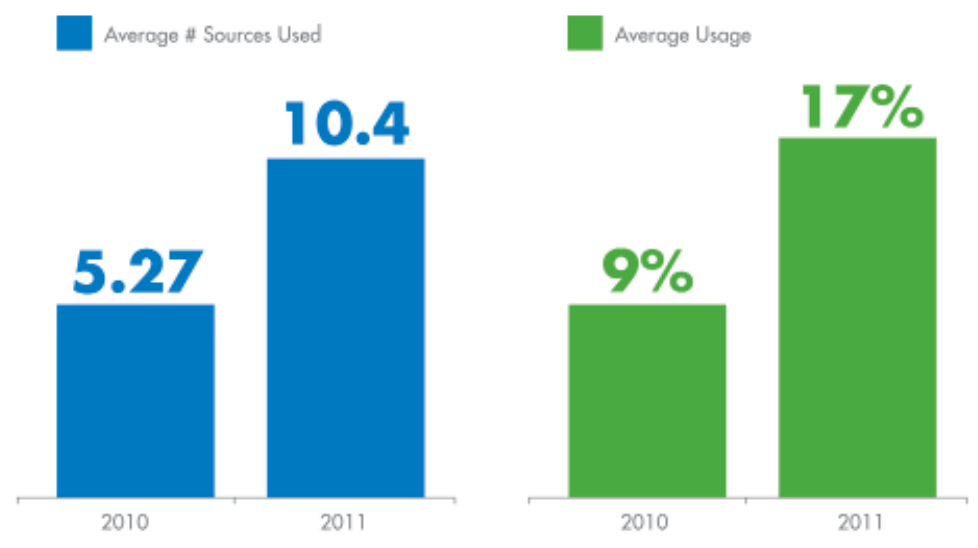

Source: Google/Shopper Sciences, Zero Moment of Truth Macro Study Industry Studies, U.S., April 2011 
В большинстве категорий ZMOT быстро стал ведущим источником информации. FMOT по прежнему является сильным игроком для категорий здоровье ОТС, здоровье и красота, продукты питания и рестораны, но значение FMOT 76\% для категории рестораны является наименьшим из всех, которые получали Shopper Sciences для этой категории в сравнении с предыдущими годами.

Рисунок А-2: Используемые источники - прояв^ение стиму^а, FMOT и ZMOT по категориям

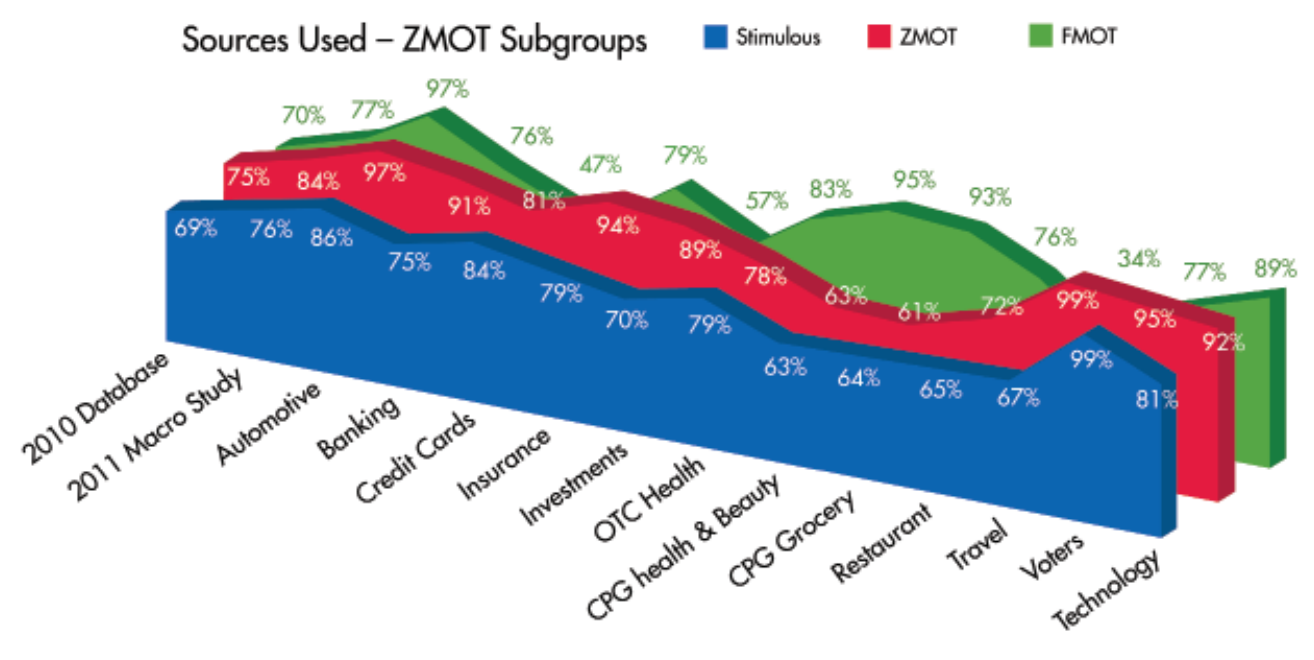

Q2 When you were considering purchasing [PRODUCT], what sources of information did you seek out to help with your decision?

Base: $\mathrm{N}=5,003$

Source: Google/Shopper Sciences, Zero Moment of Truth Macro and Industry Studies, U.S., April 2011

Sample sizes for each category noted in appendix Figure A-10

\section{Данные тепдовой карты}

Как читать тепловые карты (Рисунки А-3 и А-4): временная последовательность отмечена на оси X, слева направо, на ней отмечены точки на пути к покупке, в которых этот источник может использоваться. Размер и яркость точки показывает, насколько интенсивно используется источник. По оси Ү, чем выше нарисованы точки, тем большее влияние имеет источник на формирование решения покупателя о покупке. 
Рисунок А-3: ВозАействие использования поисковых машин по категориям

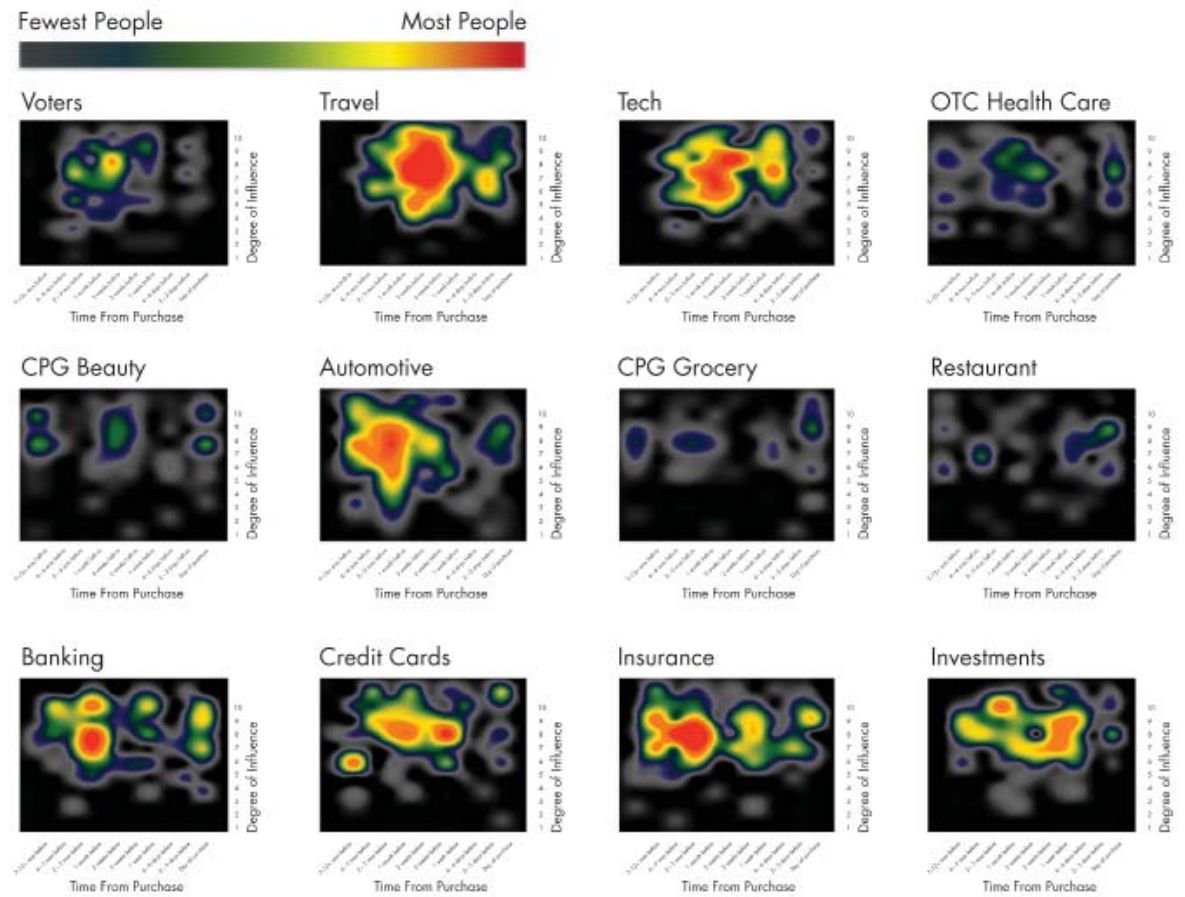

Source: Google/Shopper Sciences, Zero Moment of Truth Industry Studies, U.S., April 2011

Sample sizes for each category noted in appendix Figure A-10

Рисунок А-4: ВозАействие телевизионной рекламы по категориям

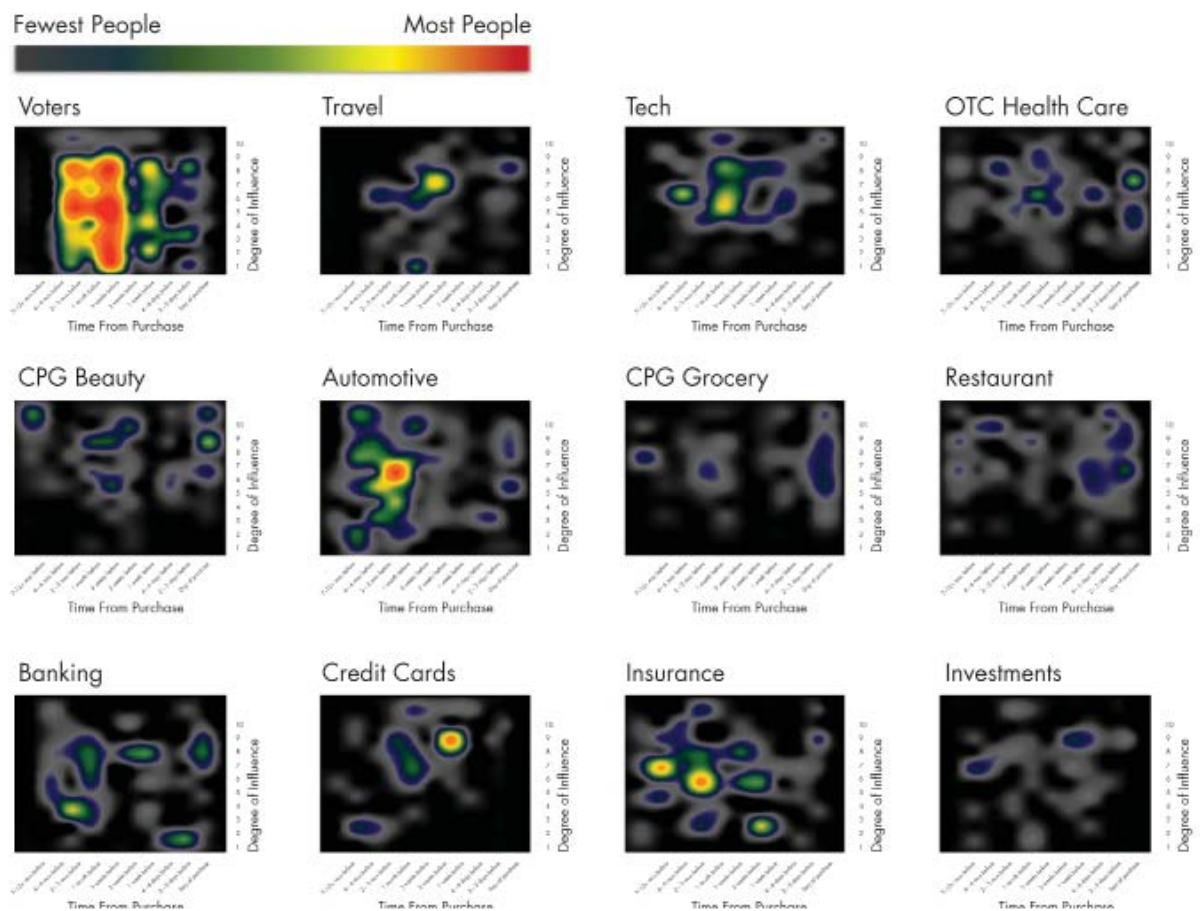

Source: Google/Shopper Sciences, Zero Moment of Truth Industry Studies, U.S., April 2011

Sample sizes for each category noted in appendix Figure A-10 
Более молодые покупатели в среднем использовали больше источников, и с большей вероятностью делились своим опытом посредством SMOT и использования Интернет для поиска сведений о своей покупке.

Рисунок A-5: Стимул, ZMOT, FMOT и SMOT по возрастным группам

\begin{tabular}{|c|c|c|c|c|}
\hline Age & Stimulus & ZMOT & FMOT & SMOT \\
\hline $18-34(\mathrm{~N}=1,594)$ & $82 \%$ & $91 \%$ & $81 \%$ & $70 \%$ \\
\hline $35-49(\mathrm{~N}=1,112)$ & $77 \%$ & $85 \%$ & $75 \%$ & $62 \%$ \\
\hline $50+(\mathrm{N}=2,297)$ & $72 \%$ & $79 \%$ & $76 \%$ & $51 \%$ \\
\hline
\end{tabular}

Source: Google/Shopper Sciences, Zero Moment of Truth Macro Study, U.S., April 2011

Рисунок А-6: Использование источников, тактическое Интернет и брэна поведение по возрастным группам

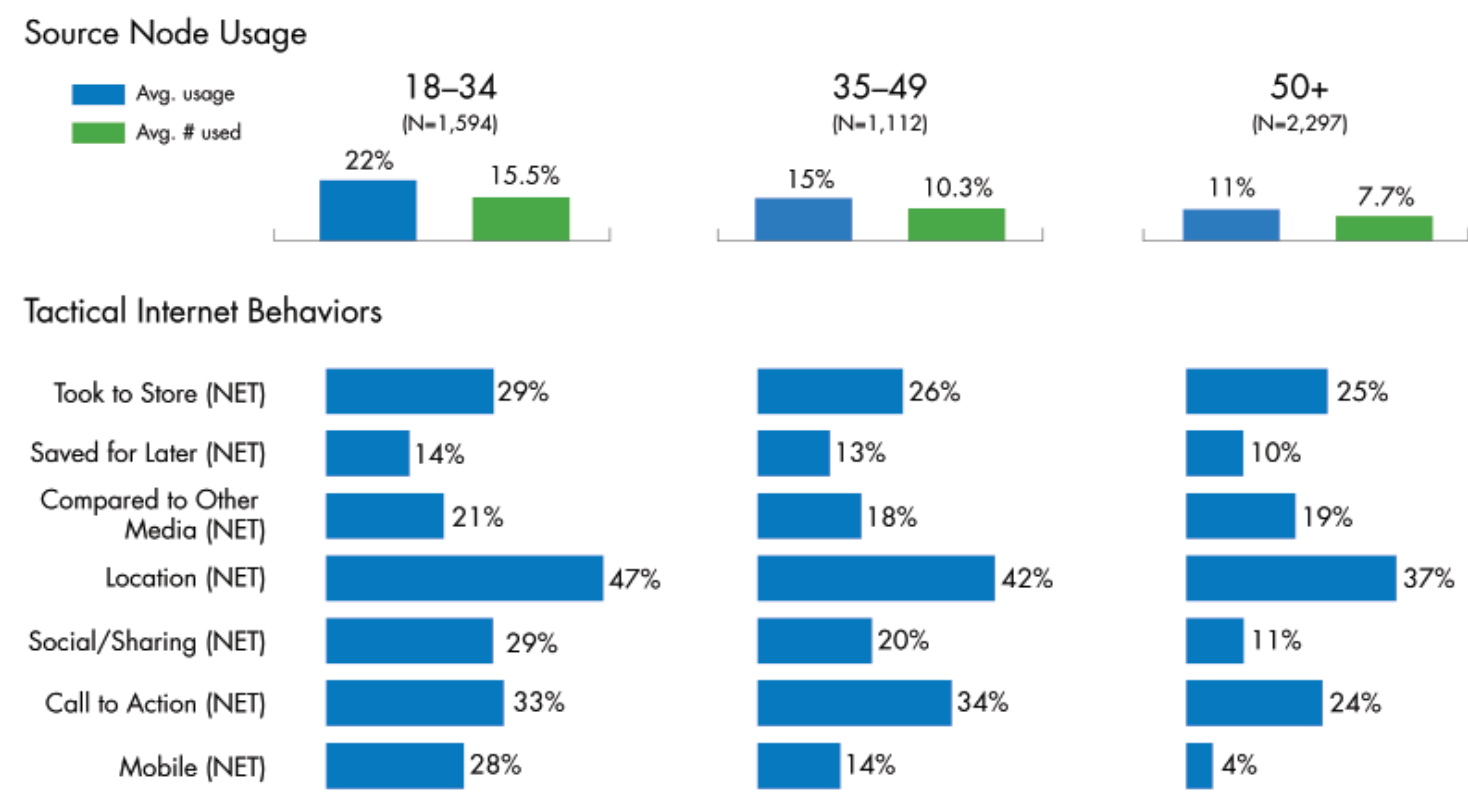

Brand in Mind
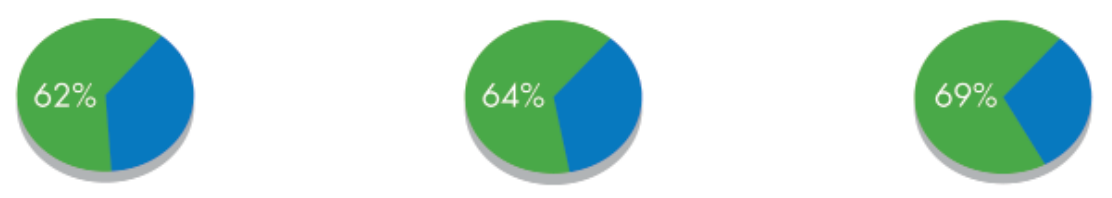

Source: Google/Shopper Sciences, Zero Moment of Truth Macro Study, U.S., April 2011 
Рисунок A-7: Стимул, ZMOT, FMOT и SMOT по Аемографиическим группам

\begin{tabular}{|l|c|c|c|c|}
\hline \multicolumn{1}{|c|}{ Demographic Group } & Stimulus & ZMOT & FMOT & SMOT \\
\hline $\begin{array}{l}\text { General Population } \\
(\mathrm{N}=5,003)\end{array}$ & $76 \%$ & $84 \%$ & $77 \%$ & $59 \%$ \\
\hline $\begin{array}{l}\text { Caucasian } \\
(\mathrm{N}=4,028)\end{array}$ & $74 \%$ & $83 \%$ & $76 \%$ & $57 \%$ \\
\hline $\begin{array}{l}\text { African American } \\
(\mathrm{N}=346)\end{array}$ & $87 \%$ & $88 \%$ & $88 \%$ & $71 \%$ \\
\hline Hispanic (N=225) & $86 \%$ & $87 \%$ & $85 \%$ & $73 \%$ \\
\hline Asian (N=294) & $89 \%$ & $93 \%$ & $84 \%$ & $76 \%$ \\
\hline Other (N=36) & $72 \%$ & $89 \%$ & $70 \%$ & $55 \%$ \\
\hline
\end{tabular}

Note: N=74 elected "Prefer Not to Say" for ethnicity question.

Source: Google/Shopper Sciences, Zero Moment of Truth Macro Study, U.S., April 2011

Рисунок А-8: Использование источников и тактическое Интернет и брэнА поведение по демографическим группам

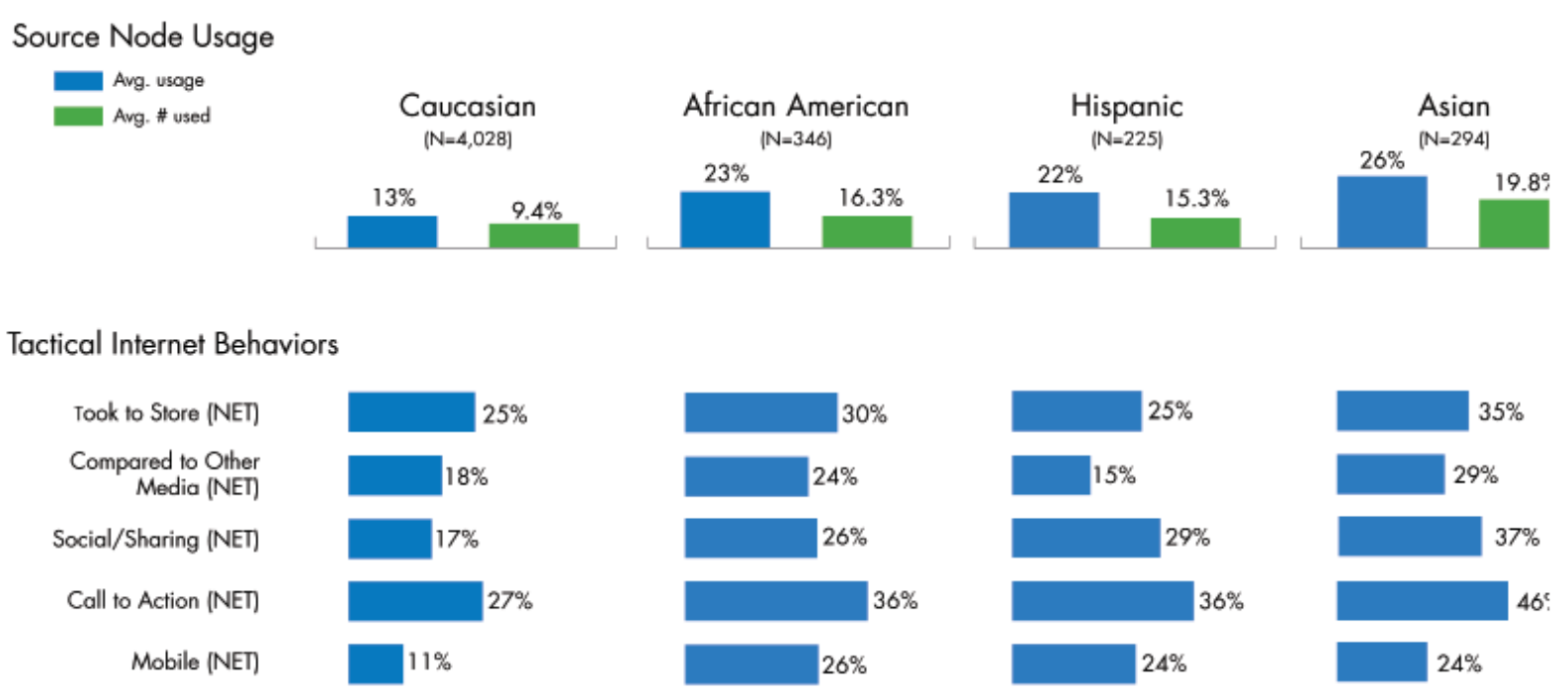

Source: Google/Shopper Sciences, Zero Moment of Truth Macro Study, U.S., April 2011 
Рисунок А-8: Определения, использованные в совместном исслеАовании Нулевого Момента Истины Google/Shopper Sciences, проведённого в США и опубликованного в апреле 2011 гола.

\section{Стимул}

Увидел(а) рекламу, будучи онлайн

Видел(а)/пробовал(а) продукт в доме друга/члена семьи

Я вырос(ла) на этом брэнде

Видел(а)/читал(а) объявления в журнале

Видел(а) рекламу на наружнем рекламном стенде

Прочитал(а) журнальные статьи/отзывы/информацию

Видел(а) рекламу в газете/газетном вложении

Прочитал(а) газетные статьи/отзывы/информацию

Искал(а) брэнды/ритейлеров в Жёлтых Страницах

Посетил(а) шоу или событие, где демонстрировали продукт

Получил(а) письмо дома от брэнда/производителя (каталог, брошюра)

Получил(а) письмо дома от магазина/ритейлера (каталог, брошюра)

Прочитал(a) информацию в етаil сообщении, полученном от брэнда/производителя

Прочитал(а) информацию в етаil сообщении, полученном от магазина/ритейлера

Попробовал(а) образец/испытал(а) продукт на специальном событии

Услышал(а) обсуждение продукта по радио

Увидел(а) рекламу по ТВ

Смотрел(а) ТВ шоу, посвящённое продукту

\section{ZMOT (Нулевой Момент Истины)}

Разговаривал(а) с друзьями/семьёй о продукте

Искал(а) онлайн, с помощью поисковой машины

Сравнивал(а) продукты онлайн

Нашёл(ла) информацию на сайте брэнда/производителя продукта

Прочитал(а) отзывы и рекомендации о продукте онлайн

Нашёл(ла) информацию на сайте магазина/ритейлера

Прочитал(а) комментарии, которые следовали за статьёй/мнением онлайн

Стал(а) другом/последователем/отметил(a) ("liked") брэнд

Посмотрел(а) видео о продукте онлайн

Прочитал(а)/посетил(а) блог, в котором велось обсуждение продукта

Искал(а) информацию в Интернет с помощью мобильного телефона перед совершением покупок

Разговарвал(а) с представителем клиентского сервиса онлайн

Искал(а) информацию в Интернет с помощью мобильного телефона в магазине

Увидел(а) упоминание о продукте на сайте социальной сети типа Facebook

Получил(а) рекомендацию от друга онлайн

Оставил(a) комментарий о продукте, упомянутом на сайте социальной сети типа Facebook 
Получил(а) купон или информацию о ценах от кого-то на сайте социальной сети Прокомментировал(а) в блоге, где велось обсуждение продукта

Искал(а) купон при помощи мобильного телефона перед покупкой Увидел(а) рекламу/купон, отправленные на мой мобильный телефон Искал(а) купоны на сайте ритейлера/магазина Получил(а) сообщение на свой мобильный телефон от брэнда/производителя Искал(а) купон с помощью моего мобильного телефона в магазине Искал(а) купоны на сайте брэнда/производителя продукта Участвовал(а) в чате или онлайн обсуждении продукта Использовал(a) мой мобильный телефон для сканирования 2D баркода/QR кода в магазине Читал(а)/посетил(а) форум/доску объявлений о продукте Общался(лась) с представителем клиентского сервиса/продавцом по email Оставил(а) комментарий о продукте на форуме/доске сообщений

\section{FMOT (Первый Момент Истины)}

Попробовал(а) образец/испытал(а) продукт в магазине

Разговаривал(а) с продавцом в магазине

Разговаривал(а) с представителем клиентского сервиса по телефону

Изучал(а) упаковку продукта в магазине

Читал(а) брошюру/буклет о продукте в магазине

Использовал(а) купон на продукт, полученный в магазине

Использовал(а) компьютер в магазине для поиска сведений о продукте

Использовал(а) карту лояльности/карту постоянного покупателя

Использовал(а) подарочную карту/бонусную карту

\section{SMOT (Второй Момент Истины)}

Рассказал(а) друзьям/семье Рассказал(а) коллеге по работе Принял(а) участие в опросе Написал(а) отзыв на вебсайте Написал(a) об этом на странице Facebook Написал(а) об этом в Twitter Написал(а) об этом в блоге 
Таблица А-10: Опрелеления категорий покупателей и размеры выборки

\begin{tabular}{|c|c|c|}
\hline Категория & $\begin{array}{l}\text { Размер выборки } \\
\text { покупателей } \\
\text { в исслеАовании }\end{array}$ & $\begin{array}{l}\text { Oпрелеление покупателей- } \\
\text { взрослые в возрасте от } 18 \text { Ао } \\
70 \text { лет, которые принимали } \\
\text { решение непосреАственно } \\
\text { или участвовали в принятии } \\
\text { решения И кто: }\end{array}$ \\
\hline Автомобили & 500 & $\begin{array}{l}\text { Купили новый автомобиль в тече- } \\
\text { ние } 2 \text { последних лет }\end{array}$ \\
\hline $\begin{array}{l}\text { Технологии } \\
\text { (потребительская } \\
\text { электроника) }\end{array}$ & 500 & $\begin{array}{l}\text { Купили технологическое изде- } \\
\text { лие персонального применения } \\
\text { в течение последних } 2 \text { месяцев. } \\
\text { Приведённые примеры включают } \\
\text { в себя: компьютер, ноутбук, DVD- } \\
\text { проигрыватель, Blu-Ray проигры- } \\
\text { ватель, цифровая камера, мобиль- } \\
\text { ный телефон, iPad, телевизор, } \\
\text { видеокамера и т.п. }\end{array}$ \\
\hline Избиратели & 503 & $\begin{array}{l}\text { Зарегистрированный в США из- } \\
\text { биратель, который голосовал на } \\
\text { промежуточных выборах в США в } \\
2010 \text { году }\end{array}$ \\
\hline Путешествия & 500 & $\begin{array}{l}\text { Оплатили поездку в течение по- } \\
\text { следних } 6 \text { месяцев }\end{array}$ \\
\hline ОТС здоровье & 500 & $\begin{array}{l}\text { Покупали ОТС препараты, вита- } \\
\text { мины, или принадлежности для } \\
\text { здоровья в течение последних } 30 \\
\text { дней }\end{array}$ \\
\hline $\begin{array}{l}\text { Потребительские товары: } \\
\text { продукты питания }\end{array}$ & 500 & $\begin{array}{l}\text { Покупали продукты питания в } \\
\text { течение последних } 2 \text { недель }\end{array}$ \\
\hline $\begin{array}{l}\text { Потребительские товары: } \\
\text { Здоровье/красота /личная } \\
\text { гигиена }\end{array}$ & 500 & $\begin{array}{l}\text { Покупали товары для здоровья, } \\
\text { красоты или личной гигиены в } \\
\text { течение последних } 2 \text { недель. При- } \\
\text { ведённые примеры включали: } \\
\text { косметика, шампуни, дезодоранты, } \\
\text { средства по уходу за кожей, зубная } \\
\text { паста и т.п. }\end{array}$ \\
\hline Рестораны & 500 & $\begin{array}{l}\text { Посетили ресторан быстрого } \\
\text { питания или обычный ресторан в } \\
\text { течение последних } 2 \text { недель }\end{array}$ \\
\hline
\end{tabular}




\begin{tabular}{|l|l|l|}
\hline Банки & 250 & $\begin{array}{l}\text { Перешли в новый банк или откры- } \\
\text { ли новый банковский счёт в тече- } \\
\text { ние последних 6 месяцев }\end{array}$ \\
\hline Кредитные карты & 250 & $\begin{array}{l}\text { Подали заявку на новую кредит- } \\
\text { ную карту в течение последних 6 } \\
\text { месяцев }\end{array}$ \\
\hline Страхование & $\begin{array}{l}\text { Купили новый полис страхования } \\
\text { автомобиля или жилья, или полис } \\
\text { страхования жизни в течение по- } \\
\text { следних 6 месяцев }\end{array}$ \\
\hline Инвестиции & $\begin{array}{l}\text { Перешли в новую инвестиционную } \\
\text { компанию, открыли новый инве- } \\
\text { стиционный счёт или покупали } \\
\text { акции, правительственные обли- } \\
\text { гации или казначейские векселя в } \\
\text { течение последних 6 месяцев }\end{array}$ \\
\hline
\end{tabular}




\section{С н О С к и}

\section{ГАава 1}

\section{Меняем своА правия}

1. Насколько мне известно, первый раз этот термин был использован в отчёте SymphonyIRI Group в октябре 2009 года: “Zero-Moment of Truth: Redefining the Consumer Decision Making Process."

2. “The New Info Shopper," Penn, Schoen \& Berland Associates, 2009

3. Google/Ipsos OTX MediaCT, “The Mobile Movement Study," April 2011, N=5,000

4. BabyCenter Study on Google Search, Nov. 2009

\section{Глава 2}

\section{Новая Ментальная Молель}

1. eMarketer, “U.S. Total Media and Online Ad Spending," Nov. 2010

2. Google/Shopper Sciences, Zero Moment of Truth Macro Study, U.S., April 2011

3. Международная Ассоциация Атлетических Федераций

\section{Глава 3}

\section{Кругом ZMOT}

1. Внутренние данные Google по мобильным устройствам, 2011

2. Внутренние данные Google, 2010

3. Согласно онлайн-инструменту Kelley Blue Book с характеристиками на апрель 2011 года

4. Google/Shopper Sciences, Zero Moment of Truth Automotive Study, U.S., April 2011

5. Google, Incremental Clicks Impact of Search Advertising Analysis, N=446 campaigns, Google, U.S. Анализ будет опубликован в июне 2011 года и размещён на research.google.com.

6. "In-Store Sales Begin at Home" by Ellen Byron, The Wall Street Journal, April 25, 2011. Эта статья отчасти основана на совместном опросе Booz \& Co. и Grocery Manufacturers Association.

\section{ГАава 4}

Рейтинги и отзывы: из уст в МОт

Нет сносок 


\section{ГАава 5}

Внимание наравне с остальными, а не в послеАнюю очереАь

1. Внутренние данные Google, май 2011

2. Search Matched Market Food Consortium Study, Google/SymphonyIRI, март 2010

\section{Глава 6}

\section{Как завоевать ZMOT}

1. Google Keyword Tool, апрель 2011

2. Google/Shopper Sciences, Zero Moment of Truth Macro Study, U.S., апрель 2011

3. Исследовательское видео Google “The Mobile Movement”, 2011

4. Внутренние данные Google по мобильным устройствам, 2011

5. Внутренние данные Google по мобильным устройствам, 2011

6. Может ли YouTube получить доход масштабов Google?, AdAge.com, 1 февраля, 2010

7. YouTube Incremental Research Benchmark Study, Google, Germany, 2010

8. Цитата Маршалла Брикмана в The New York Times, 21 августа, 1977: Arts \& Leisure, стр. 83

\section{ГАава 7}

\section{Что Аальше?}

1. Согласно исследованию Synovate 2009 года, охватившему 8,000 человек в 11 странах, процитировано Reuters 4 сентября 2009 года

2. GigaOM, Feb. 1, 2009 


\section{БЛАГОААРНОСТИ}

За время работы над этой книгой мне посчастливилось получить мысли и вводные от некоторых из любимых мною маркетологов и мыслителей.

Бет Комсток из General Electric, Марк Аддикс из General Mills, Ким Кадлек из Johnson \& Johnson и Венди Кларк из Coca-Cola поделились сведениями о том, как работают co ZMOT некоторые из самых больших мировых брэндов. Ришад Тобаковала из VivaKi добавил необходимые размышления о лидерстве. Тина Шарки из BabyCenter, Боб Такер из gravitytank и Деннис Кари из Bally Fitness показали мне, насколько мощным может быть ZMOT для некоторых очень конкретных вертикалей.

Дэвид Алмасы из Edelman Public Relations дал мне направления общественной политики и потрясающий рассказ про ZMOT во время дебатов о здравоохранении. Алия Байлор из Make My Cake, Мэнди Скотт из Mandy Scott Flowers, Мэтт Николс из Pandora и Мария Бауг из Butter Lane Cupcakes показали мне, как работает ZMOT для небольшого и местного бизнеса.

Мэтт Муг из Viewpoints и Бретт Харт из Bazaarvoice рассказали мне многое о пользовательских рейтингах и отзывах, а также о том, как они укладываются в корпоративную экосистему. Профессоры Дэйв Рейбштейн и Джерри Винд из The Wharton School поделились со мной академической точкой зрения, а Джон Бирмингем из Университета DeVry поделился пониманием маркетинга для академической аудитории.

Передаю свои благодарности Дине Хауэлл из Saatchi \& Saatchi X за её прекрасное введение, а также Кевину Робертсу и А.Г. Лафли за разрешение цитировать Lovemarks.

Джон Росс, Мэнди Брукс и остальные члены команды Shopper Sciences проделали невероятную работу по приведению концепции ZMOT в жизнь последством нашего макро исследования. Их глубокое понимание, внимательность и любовь к данным были ясны с первого дня проекта и мы никогда не достигли бы таких результатов без них.

B Google, большое спасибо Дэннису Вудсайд за первоначальное влияние и поддержку во время этого проекта. Я также должен поблагодарить Авинаша Каушика, который оказал огромную помощь по теме измерения ZMOT. Его блог, Бритва Оккама, необходимо обязательно прочитать всем, кто хочет использовать веб аналитику для измерения успеха и достижения ясности мышления. Другие коллеги из Google, включая Лорэйн Тухилл, Лизу Гевелбер и Катерин Рое, поделились своими замечательными историями и размышлениями о современной мобильности и ZMOT.

Особые благодарности я передаю Дженни Ли и Деборе Поуснер, моим ZMOT помощникам, за их энтузиазм и креативность в процессе перевода ZMOT из концепции в текст, видео и так далее. 
Я благодарю Чипа Кидда за его прекрасную обложку и Марка Истмана и команду Harding за их поддержку в плане графики на всём протяжении книги.

Для видеоверсии этой книги Рэйчел Вебстер и Мосс Левенсон из Captain \& The Fox проделали безукоризненную работу по проведению интервью, даже несмотря на то, что Рэйчел была занята ребёнком - момент истины совсем другого типа.

И конечно, я выражаю свою искреннюю благодарность Фрицу Холцнагелю за его помощь облачить это всё в слова. Это было долгое путешествие и у меня не могло быть лучшего партнёра во время поездки.

\section{- Джим Лесински}

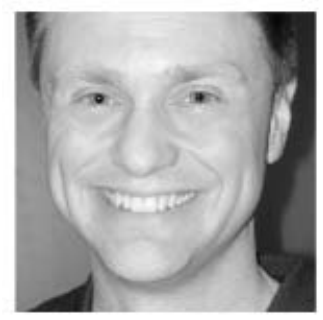

\section{ОБ АВTOPE}

Я являюсь управляющим директором подразделения U.S. Sales \& Service в Google, и работаю с крупнейшими брэндовыми маркетологами и партнёрами из медийных агентств. Я работаю в Чикагском офисе Google и имею более чем 20-летний интегральный опыт в маркетинге.

До прихода в Google в 2006 году, я занимал руководящие позиции в рекламных агентствах DDB, marchFirst, Young \& Rubicam, и EuroRSCG.

Сегодня я помогаю маркетологам справляться с вызовами во всех фазах маркетинга, от брэндирования и понимания потребителей до онлайн медиапрограмм и анализа данных. Меня часто приглашают на выступления в университетах, на отраслевые мероприятия и конференции, включая ANA, АМА и ВМА.

Я получил степень МВА в университете Иллинойса и степень бакалавра искусств в университете Нотр Дам. Но я занимаюсь не только маркетингом всё своё время, моя страсть - винтажный джаз, который я играю, коллекционирую и обсуждаю в блогах. 
Winning the Zero Moment of Truth

Copyright (c) 2011 by Google Inc. All rights reserved.

Мы приглашаем вас распространять эту книгу среди ваших друзей и коллег, размещать её на своём вебсайте, или распространять бесплатные электронные версии иным способом. Она должна сохраняться в своей оригинальной форме, без удаления и добавления текста или изображений. Книгу нельзя продавать или использовать иными способами для получения коммерческой прибыли. Google Inc. оставляет за собой все права на эту книгу в печатном, видео и всех остальных форматах.

Перевод книги на русский язык (с) 2011 Станислав Коротыгин, http://www.korden.ru/ZMOT/ 
ZMOT Z

ZMOT ZMO

ZMOT ZMOT Z

ZMOT ZMOT ZMOT ZMOT Z

ZMOT ZMOT

ZMOT ZMOT ZM

ZTMOT ZMOTZ Z

ZMOT ZMOT ZN

ZMOT ZMOT ZN

ZMOT ZMOT ZN

ZMOT

МOT ZMOT ZMOT ZMOT ZMOT ZMOT ZMOT ZMOT ZMOT ZMOT ZMOT ZMOT ZMOT Z

ZMOT ZMOT ZMOT ZMOT ZMOT ZMOT ZMOT ZMOT ZMOT ZMOT ZMOT ZMOT ZMO

ZMOT ZMOT ZMOT ZMOT ZMOT ZMOT ZMOT ZMOT ZMOT ZMOT ZMOT ZMOT Zl MOT ZMOT ZMOT ZMOT ZMOT ZMOT ZMOT ZMOT ZMOT ZMOT ZMOT ZMOT ZMOT Z ZMOT ZMOT ZMOT ZMOT ZMOT ZMOT ZMOT ZMOT ZMOT ZMOT ZMOT ZMOT ZMO ZMOT ZMOT ZMOT ZMOT ZMOT ZMOT ZMOT ZMOT ZMOT ZMOT ZMOT ZMOT Z МOT ZMOT ZMOT ZMOT ZMOT ZMOT ZMOT ZMOT ZMOT ZMOT ZMOT ZMOT ZMOT Z ZMOT ZMOT ZMOT ZMOT zMOT ZMOT ZMOT ZMOT ZMOT ZMOT ZMOT ZMOT ZMO ZMOT ZMOT ZMOT ZMOT ZMOT ZMOT ZMOT ZMOT ZMOT ZMOT ZMOT Z МOT ZMOT ZMOT ZMOT ZMOT ZMOT ZMOT ZMOT ZMOT ZMOT ZMOT ZMOT ZMOT Z ZMOT ZMOT ZMOT ZMOT ZMOT ZMOT ZMOT ZMOT ZMOT ZMOT ZMOT ZMO ZMOT ZMOT ZMOT ZMOT ZMOT ZMOT ZMOT ZMOT ZMOT ZMOT ZMOT ZMOT Z. MOT ZMOT ZMOT ZMOT ZMOT ZMOT ZMOT ZMOT ZMOT ZMOT ZMOT ZMOT ZMOT ZMOT ZMOT ZMOT ZMOT ZMOT ZMOT ZMOT ZMOT ZMOT ZMOT ZMOT ZMOT ZMO ZMOT ZMOT ZMOT ZMOT ZMOT ZMOT ZMOT ZMOT ZMOT ZMOT ZMOT ZMOT ZI ZMOT ZMOT ZMO ZMOT ZMOT ZMOT ZMOT ZMOT ZMOT ZMOT ZMOT ZMOT ZMOT ZMOT ZMOT ZMO ZMOT ZMOT ZMOT ZMOT ZMOT ZMOT ZMOT ZMOT ZM MOT ZMOT ZMOT ZMOT ZMOT ZMOT ZMOT ZMOT Z ZMOT ZMOT ZMOT ZMOT ZMOT ZMOT ZMOT ZMOT

TMOT ZMOT ZMOT Z

ZMOT ZMOT ZN МOT ZMOT ZMOT ZMOT

ZMOT ZMOT ZN MOT ZMOT ZMOT ZMOT

ZMOT ZMOT ZI МOT ZMOT ZMOT ZMOT Z

ZMOT ZMOT ZI ZMOT ZMOT ZN ZMOT ZMOT ZM ZMOT ZMOT ZN ZMOT ZMOT ZMOT ZMO МОT ZMOT ZMC ZMOT ZMOT ZN ZMOT ZMOT ZN ZMOT ZMOT ZN ZMOT ZMO ZMOT ZMOT ZN ZMOT ZMOT ZM ZMOT ZMOT ZN ZMOT Z

\section{ZMOT ZMOT} ZMOT ZMOT ZM ZMOT ZMOT ZN

\section{(10} OT ZMOT Z LTHO
MOTZM ZMOT ZMOT ZN ZMOT ZMOT ZN ZMOT ZMOT ZN ZMOT ZMOT ZM ZMOT ZMOT ZMOT ZMO ZMOT ZMOT ZM ZMOT ZMOT ZN MOT ZMOT ZMOT ZMOT ZM ZMOT ZMOT Z^ ZMOT ZMOT ZN ZMOT ZMOT ZN ZMOT ZMOT ZMOT ZN ZMOT ZMOT ZMOT ZMOT Z ZMOT ZMOT ZMOT ZMO ZMOT ZMOT ZMOT ZMOT ZMOT ZMOT ZMOT ZMOT ZMC ZMOT ZMOT ZMOT ZMOT ZMOT ZMOT ZMOT ZMOT ZM МOT ZMOT

\section{ZMOT}

ОT ZMOT ZMOT ZMOT ZMOT ZMOT ZMOT ZMOT ZMOT ZM ZMOT ZMOT ZMOT ZMO ZMOT ZMOT ZMOT ZMOT ZMOT ZMOT ZMOT ZMOT ZMC 
Google 